\title{
GROWTH, INCOME DistribUtion, AND WELL- BEING: COMPARISONS ACROSS SPACE AND TIME
}

\author{
CAROLA GRÜN \\ STEPHAN KLASEN
}

CESIFO WORKING PAPER NO. 837

CAtegory 5: Fiscal Policy, Macroeconomics and Growth

JANUARY 2003

\begin{abstract}
Presented at CESifo CONFERENCE ON Globalisation, INEQUALITY AND WELL-BEING, NOVEMBER 2002
\end{abstract}

\footnotetext{
An electronic version of the paper may be downloaded - from the SSRN website: www.SSRN.com

- from the CESifo website: www.CESifo.de
} 


\title{
GROWTH, INCOME DisTRIBUTION, AND WELL- BEING: COMPARISONS ACROSS SPACE AND TIME
}

\begin{abstract}
We use several well-being measures that combine average income with a measure of inequality to undertake international, intertemporal, and global comparisons of well-being. The conclusions emerging from the analysis are that our well-being measures drastically change our impression of levels of well-being at the national and, more so, at the global level. They also significantly affect the ranking of countries, when compared to rankings based on real incomes. The impact on these measures on temporal trends in well-being is smaller on average, but significant for a number of countries where inequality changed considerably in past decades. These results appear not very sensitive to the data on inequality which this analysis is based upon. However, since the inclusion of inequality has an important impact on wellbeing comparisons and it is of great importance to generate more consistent and intertemporally as well as internationally comparable data on inequality that are necessary for such comparisons.
\end{abstract}

JEL Classification: I31, D63.

Carola Grün
Department of Economics
University of Munich
80539 Munich
Germany

Germany

\author{
Stephan Klasen \\ Department of Economics \\ University of Munich \\ 80539 Munich \\ Germany \\ klasen@lrz.uni-muenchen.de
}

We would like to thank Tony Atkinson, François Bourguignon, Syed Ahsan, James Foster, and Michael Ward for helpful discussions on this topic. Comments on earlier versions of the paper from discussants and participants at the 22nd IARIW conference in Cracow 2000, the workshop on income distribution in Milan 2002 as well as the CESifo conference on globalisation, inequality and well-being in Munich 2002 were also much appreciated. 


\section{Introduction}

Despite its well-known short-comings, GNP per capita is still the most widely used indicator for comparisons of well-being across countries; and the per capita growth rate is still the most common indicator of changes in well-being. ${ }^{1}$

The exclusive reliance on this measure is largely due to pragmatic grounds. GNP (and GDP) are important measures of production possibility and business cycles, which ensure that great efforts are made to measure them timely, accurately, and according to internationally agreed standards. With these data readily available, it is tempting to rely on them for international and intertemporal comparisons of well-being. Moreover, it is argued by many that GNP per capita and growth of per capita income is still the best available proxy for changes in well-being as it is highly correlated with more complete or more broad-based measures of well-being (e.g. Dollar and Kraay, 2000; Ravallion, 1997).

Nevertheless, it continues to be the case that its neglect of income distribution is one of the most serious short-comings of GNP as an indicator of welfare. In particular, a broad range of philosophical approaches to the measurement of welfare (ranging from utilitarianism with some very reasonable assumptions about utility functions to Rawlsian reasoning or Sen's capability approach) would suggest that, ceteris paribus, high economic inequality reduces aggregate well-being. In fact, there exists a range of measures for wellbeing that make use of this insight and combine mean income with some measure of income inequality to arrive at better measures of welfare than average income alone (e.g. Atkinson, 1970; Sen, 1973; Dagum, 1990; Ahluwalia and Chenery, 1974).

In the past the application of those measures was limited, mainly because of lack of data on income distribution. Recent years, however, have seen great advances being made in the generation of data on income inequality (e.g. Deininger and Squire, 1996; Gottschalk and Smeeding, 1997; WIID, 2000). Thus it seems natural to apply well-being measures that combine GNP per capita and income distribution to these new data and investigate to what extent these measures will generate comparisons of well-being across space and time that are substantially different from pure per capita income comparisons. This exercise is the purpose of this paper.

We find that the measures that include income inequality in the assessment of wellbeing have a significant influence on international comparisons of well-being. Several countries, including Brazil, Mexico, Chile, but also the US have considerably lower levels of well-being and thus rankings of well-being than suggested by per capita income, while other countries, including Indonesia, Bangladesh, Finland, and Belgium have a higher wellbeing rank than their income rank. For many countries, these findings are quite robust to using different data sources; for others, including some OECD countries, the international comparisons are substantially affected by the choice of data set. At the same time, we find that consideration of inequality has a comparatively minor impact on intertemporal comparisons of well-being as in most countries of the world income distribution has remained fairly stable over the period of time considered here (esp. when compared to the much larger fluctuations in income growth, see also Lundberg and Squire, 1999). Only in

\footnotetext{
${ }^{1}$ There are other indicators, such as the Human Development Index and related measures, that have attempted to generate alternatives to this exclusive reliance on income, but they have been criticized for their choice of indicators, aggregation rules, and their neglect of distribution of the achievements considered (see Srinivasan, 1994; Ravallion, 1997).
} 
a few countries (including nearly all transition countries, Britain, and the US) does the consideration of inequality markedly change assessments of changes in well-being. Finally, we find that due to the extremely large global income inequality, global well-being is very much lower than it would be if incomes were more equally distributed. For the sample of countries that we consider in our assessment of global income inequality (which unfortunately excludes many of the poorest countries), changes in global well-being are larger than suggested by the income growth measure as inequality seems to have declined in our sample of countries, especially in the 1980s.

It should be pointed out at the start that this paper presents tentative results of an exercise that, to some degree, is still speculative. On the theoretical side, we do not wish to propose definitive measures of well-being. Instead, we merely wish to illustrate how reasonable ways of incorporating inequality in an assessment of well-being will change our impression of well-being across space and time. On the empirical front, our conclusions should be seen as equally tentative. While we have many more data on income inequality across space and time than we used to, the accuracy and comparability of many of them remains a huge problem (see Atkinson and Brandolini, 2001; Deininger and Squire, 1996). We have undertaken some sensitivity analyses using possibly better data available for some points in time in a limited number of countries and using regression-based adjustments. None of this can substitute for long consistent time series of internationally standardized and comparable data which are at present not available. Moreover, our international comparisons of inequality are limited to a small number of countries in the early years we consider $(1960,1970)$ so that it is difficult to say much about temporal trends in inequality and well-being in many countries. And even for these countries we often only have very irregular data points on inequality so that we cannot really talk about consistent time series. Finally, our 'global' analysis is restricted to some 80 per cent of the world's population, and the 20 per cent excluded are clearly not a random sample. To achieve such good coverage and include the most populous African countries as well, we had, in addition, to make somewhat heroic assumptions as we only have reasonable data for some 76 per cent of the world's population in 1998. Despite these short-comings, we are nevertheless confident that this analysis generates a number of important and usable findings that should be fairly robust to most of the many data problems we encounter.

The paper is organized as follows: the next section discusses the theoretical issues involved in comparing well-being across space and time. Section 3 introduces the measures of well-being we use in the paper. Section 4 discusses the data and our manipulations for this analysis. Section 5 presents the results for the international analysis, section 6 the sensitivity analysis. The results of the intertemporal comparisons are shown in section 7 and section 8 presents our global analysis. Section 9 concludes. 


\section{The Theory of Well-Being and Real-Income Com- parisons}

Despite a long history, the theory of welfare judgements across space and time continues to be beset with conceptual and practical problems. Ever since it became evident that social choice theory was not yielding acceptable ${ }^{2}$ procedures for making social welfare judgements, such judgements have been based on axiomatic approaches to welfare measurement. Those are based on a conceptualization of what constitutes welfare and then the derivation of an indicator that, under certain stated assumptions, can adequately measure the chosen concept.

Applying such measures to welfare comparisons across space and time generate additional problems. Those are discussed in detail in Sen $(1982,1984)$ and will only be summarized here. In particular, the theory of welfare comparisons is based on situational comparisons, i.e. whether a person would hypothetically prefer situation A to B. This comparison thus takes place at the same time and is done by the same person. Intertemporal or international welfare comparisons, however, address different questions. Intertemporal comparisons have to contend with the problem that the persons are not evaluating the welfare of two situations simultaneously, but sequentially. This may generate problems if overall perceptions of welfare or tastes have changed over time (in addition to the problem that not all the people are alive in both periods). Comparisons across space, as done in inter-country comparisons, are even more difficult as now the persons differ whose welfare is being compared. ${ }^{3}$ The comparison could be made using the price (or other welfare weight) vectors of either country, which would not necessarily generate the same result. In addition to this theoretical problem, the comparability of prices also throws up another problem, namely the appropriate exchange rate for international comparisons. In the past, most real income comparisons were based on official exchange rates despite the knowledge that they are often distorted as a result of speculation and currency restrictions, and that they imply a systematic underevaluation of the non-traded sector in poorer countries. In recent years, the International Comparison Programme (ICP $)^{4}$ has generated purchasing power parity estimates of GDP and GNP based on international prices that try to address these particular short-comings. ${ }^{5}$

Thus there are some important conceptual questions that relate to such comparisons. Only if one places restrictions on intertemporal changes and international differences in

\footnotetext{
${ }^{2}$ Acceptable is meant in the sense of obeying minimal requirements such as the four conditions stated by Arrow in his famous impossibility result (Arrow, 1963). See also Sen $(1973,1999)$ for a discussion.

${ }^{3}$ One could try to translate an international comparison into a situational comparison, i.e. asking the British whether they would prefer to live in Britain this year or in France this year. This throws up considerable problems, however, as it is not clear which British person should compare themselves to which French person, or whose welfare function should be used. For a discussion of those issues, see Sen (1982, 1984).

${ }^{4}$ The ICP produces estimates of the economies' main aggregates which are comparable across countries. Purchasing power parities are generated and used for converting the data into a common currency (UN, 1992).

${ }^{5}$ While the data generated by these methods are widely used, they are not beyond question. In particular, the resulting adjusted per capita incomes are sensitive to the choice of 'international prices' which is closer to the prices prevailing in rich countries (Berry, Bourguignon, and Morrison, 1991; Hill, 2000). Moreover, as section 5 reveals, PPP adjustments can differ in their outcomes as the differences between the World Bank estimates and the Penn World Tables demonstrate.
} 
preferences, these comparisons can yield meaningful outcomes. Given the ubiquity of such comparisons, it appears that most analysts are willing to make such assumptions.

The most commonly used indicator for welfare comparisons across space and time is real per capita income. ${ }^{6}$ It can be derived from utilitarian welfare economics using three alternative sets of assumptions. One set would demand everyone to have identical unchanging cardinal utility functions where income (or consumption) ${ }^{7}$ enters the utility function linearly (e.g. in the simplest form, every unit of consumption generates one unit of utility). An alternative set of assumptions could allow for more realistic concave utility functions, but would still require identical utility functions and require in addition that everyone is earning the per capita income and thus consumes the mean commodity bundle (Sen, 1984). A third set is based on Samuelson (1947) and takes an 'individualistic approach' to welfare measurement. Under this approach, we recover social welfare from individual welfare based on revealed preferences using the Pareto principle. If preferences are complete, convex, and monotonically increasing, if each person's welfare only depends on her purchases (i.e. no externalities and public goods), if there are no market imperfections on the buyer's side, and if each person is rational in the sense that her choices reflect her welfare ranking, then the ratio of market prices should equal the ratio of intra-personal weights (marginal rates of substitution) attached to these goods. These assumptions are not sufficient, however, to ensure that the market prices say anything about the valuation of a good going to two different people, as this requires interpersonal comparisons. To be able to make such interpersonal comparisons which is required for all real income comparisons, we need to assume in addition that the income distribution is 'optimal' in the sense that the ethical worth of each person's marginal dollar is equal (Samuelson, 1947).

All three sets of assumptions are problematic. While many aspects of the various approaches appear unrealistic, the need to explicitly ignore the distribution of income in a welfare comparison is particularly unpalatable. Ignoring income distribution through the assumption of linear utility functions, through the assumption of everyone having the same income, or through the assumption of income distribution being 'optimal' from a welfare point of view is all equally debatable. In fact, both theoretical considerations (e.g. declining marginal utility of income derived from convex preferences) as well as empirical observations (e.g. about risk aversion and insurance) clearly suggest that neither utility functions are linear in income or consumption, nor that the existing distribution of incomes is 'optimal' from a social welfare point of view. Instead, these theoretical and empirical considerations point to concave utility functions, i.e. that inequality reduces aggregate welfare as the marginal utility of income among the poor is much higher than among the rich. $^{8}$

Non-utilitarian views of welfare would also suggest that income inequality reduces aggregate well-being. For example, Sen's capabilitity approach (Sen, 1987) which calls for a maximization of people's capability to function (e.g. the capability to be healthy, wellnourished, adequately housed, etc.) also exhibits declining marginal returns in the income

\footnotetext{
${ }^{6}$ There are well-known omissions and distortions of GNP as a measure of the value created in an economy. These issues will not be discussed further here.

${ }^{7}$ We abstract from the difficulties associated with the treatment of saving in an indicator of welfare. For a discussion, see the paper by Osberg and Sharpe (2000).

${ }^{8}$ This is inherent also in the approach by Graaf (1957) and Sen (1982) who treat the same good going to two different people as two different goods and thus explicitly do away with the distinction between size and distribution of income as the 'welfare depends on them both' (Sen, 1982).
} 
space. ${ }^{9}$ Similarly, application of Rawlsian principles would also suggest that welfare is higher in societies where inequality is lower (Rawls, 1971). ${ }^{10}$

One approach to improve upon the welfare content of real income comparisons is therefore to jettison this neglect of income distribution and incorporate the notion of declining marginal welfare returns of income. Each of the measures proposed in the next section does precisely this in slightly different ways.

Before turning to this issue, however, it may be useful to consider one explicit objection to the incorporation of distributional issues in an assessment of well-being. In particular, it may be argued that redistribution reduces the long-term growth potential of an economy because higher inequality will lead to higher growth rates. This would suggest, that there is a trade-off between higher well-being associated with today's lower inequality and lower well-being associated with the subsequently reduced economic growth. While such dynamic considerations go beyond the scope of this analysis and would, in any case, require the inclusion of other dynamic issues (e.g. the role of savings and of depreciation of human, natural, and physical capital in long-term well-being of nations) ${ }^{11}$, there is a growing consensus that this trade-off between distribution and growth does not exist. In fact, if anything, the debate has recently shifted in the opposite direction suggesting that initial inequality lowers subsequent growth prospects rather than increases them (e.g. Deininger and Squire, 1998; Alesina and Rodrick, 1994; Clarke, 1995; Persson and Tabellini, 1994; Klasen, 1999). While these findings are still tentative and subject to some debate ${ }^{12}$, they suggest that the older claim, that high inequality is necessary for growth, does not seem to be born out by the facts (see also Klasen, 1994).

\section{The Well-Being Measures Used}

In this section we describe some measures that jointly consider per capita income and its distribution and therefore avoid the particularly problematic neglect of income distribution in a consideration of welfare. Most are well-known in the inequality literature although not all of them have been used explicitly for aggregate welfare comparisons. All share the feature that they can be summarized by the following formula:

$$
W=\mu(1-I) \text { where: } 0 \leq I \leq 1
$$

\footnotetext{
${ }^{9}$ For example, there appears to be a concave relationship between income and life expectancy, and income and educational achievement. For a discussion, see Klasen (1994).

${ }^{10}$ In the lexicographic version of the maximin principle, only the position of the worst off is relevant; if one generalizes a bit, one would get a more continuous declining marginal valuation of income. Similarly, Hirsch's views on the social limits to growth also imply declining aggregate well-being as a result of inequality. For details see Hirsch (1977) and Klasen (1994).

${ }^{11}$ One might also want to consider longevity in conjunction with income and income inequality to measure how long people are able to enjoy their incomes. For a discussion, see Berry, Bourguignon, and Morrison (1991).

${ }^{12}$ See, for example, Lundberg and Squire (1999) who regard growth and income inequality as jointly determined rather than one causing the other; they also find that inequality is particularly bad for income growth among the poor, while it has a different effect for income growth among the rich.
} 
Welfare $W$ is a function of mean income $\mu$, reduced by a measure of inequality $I$. Thus, the existing degree of inequality adjusts mean income downward to reflect the welfare loss associated with the (unequal) distribution of that mean income. We will consider several measures because there are on the one hand differences with respect to the intensity of 'welfare penalty' that is imposed. On the other hand the measures vary in the way they penalize different types of inequality.

The first measure considered here was proposed by Sen (1982) and incorporates inequality by using the Gini coefficient $G$ :

$$
S=\mu(1-G)
$$

The Sen measure can be derived by replacing Samuelson's problematic 'optimal distribution' assumption by the assumption of 'rank order weighting' (Sen, 1973). Individual incomes will be weighted according to their rank in the income distribution (with the richest person receiving rank 1 and thus the lowest weight for her income). It can also be derived from a utility function where individuals consider not only their own income, but the entire income distribution, with particular emphasis on the number of people with incomes below or above one's own (Dagum, 1990). Thus preferences are assumed to be interdependent which accords well with recent empirical findings (e.g. Easterlin, 1995; Banerjee, 1997).

A variant of this measure was proposed by Dagum (1990):

$$
D=\frac{\mu(1-G)}{1+G}=\mu\left(1-\frac{2 G}{1+G}\right)
$$

Clearly, the Dagum measure is a more extreme version of the Sen measure as it results in a higher penalty because of the denominator which imposes an additional punishment for inequality. The Dagum measure is also based on interdependent preferences and implies that people receive a further welfare penalty from the people ahead of them in the income distribution which also appears to be a reasonable assumption. ${ }^{13}$

In addition, we consider two versions of the Atkinson welfare measure. The Atkinson measure was developed as an indicator of inequality that explicitly considers the welfare loss associated with inequality in the measure (Atkinson, 1970). But one can equally well just use the way the welfare loss is calculated, the equally distributed equivalent income, as the welfare measure itself. ${ }^{14}$ This equally distributed equivalent income is the amount of income that, if distributed equally, would yield the same welfare as the actual mean income and its present (unequal) distribution (Deaton, 1997). The general form of this measure is: ${ }^{15}$

\footnotetext{
${ }^{13}$ See Dagum (1990) for a derivation and justification of this measure.

${ }^{14}$ This has been done, for example, for Britain by Jenkins (1997) and also by UNDP in deriving the gender-related development index (UNDP, 1995). For a discussion of this index, see Bardhan and Klasen (1999).

${ }^{15}$ This measure also satisfies the general form of the well-being measure $W=\mu(1-I)$ where $I=\frac{1-A}{\mu}$. See Atkinson (1970) for discussion.
} 


$$
A 2=\left[\frac{1}{N} \sum_{i=1}^{N} x_{i}^{1-\varepsilon}\right]^{\frac{1}{1-\varepsilon}}
$$

This measure depends crucially on the exponent $\varepsilon$, the aversion to inequality factor. The higher $\varepsilon$, the higher the penalty for inequality. We explicitly consider two cases, $\varepsilon=2$, denoted as $A 2$, and $\varepsilon=1(A 1)$. In the latter case, the general form of the Atkinson measure is not defined and changes to:

$$
\ln (A 1)=\frac{1}{N} \sum_{i=1}^{N} \ln \left(x_{i}\right)
$$

The Atkinson measures can be derived from social welfare functions that are additively separable functions of individual incomes. Thus they are based on individualistic utility functions where people only care about their own incomes. Inequality reduces welfare in this formulation as the utility functions considered are concave for all $\varepsilon>0$. All the measures exhibit constant relative risk aversion. The $\varepsilon=1$ has the additional property of being based on a constant elasticity utility function, suggesting that a percentage increase in income is valued the same regardless of its recipient. Such an assumption has quite a lot of intuitive appeal. While clearly $\varepsilon=2$ penalizes inequality more than $\varepsilon=1$ and is thus based on declining elasticity of income, the underlying assumption, that at twice the level of income, a percentage increase in income is valued half as much as at the lower level of income, also appears to be within the range of reasonable presumptions (see Deaton, 1997; UNDP, 1995). Such penalties of inequality are still consistent with findings from the micro literature on utility and risk. Most of the non-utilitarian theories suggested above would, in fact, likely require considerably higher inequality aversion. ${ }^{16}$ While the Atkinson measures are typically based on individual incomes, our $\mathrm{N}$ refers to income quintiles only.

A third set of measures were proposed by Ahluwalia and Chenery (1974) which presented measures that combine income growth with redistribution. In particular, they suggested a measure which they called a population-weighted or equal-weighted growth rate which is simply the arithmetic average of the growth rates of each individual (or quintile). Instead of treating a dollar increase the same regardless of its recipient, this measure treats a percentage increase the same, thus also allowing for declining marginal utility of income and exhibiting what they called the 'one person, one vote' principle of growth measurement. It turns out that this measure is a small-number approximation of the Atkinson $\varepsilon=1$ measure, which also weights a percentage increase the same regardless of its recipient. ${ }^{17}$ Thus we will not report it separately here. But the similarity between this measure and the Atkinson measure gives another quite nice justification for the Atkinson measure.

\footnotetext{
${ }^{16}$ A strict interpretation of Rawls lexicographic maximin principle would require $\varepsilon$ to be infinite (see also Atkinson, 1970).

${ }^{17}$ It can be shown that the growth in the Atkinson measure with $\varepsilon=1$ is simply the geometric mean of the growth rates of individuals (or quintiles, depending on the unit of disaggregation), while the population or equal weights measure is the arithmetic mean of the growth rates. For small numbers, one is an approximation of the other. See Klasen (1994) for a discussion and application of the Ahluwalia and Chenery measures.
} 
Similarly, their second growth measure, the welfare or poverty-weighted growth rate (which gives greater weight to income increases of the poor than the rich) is a discrete approximation of a version of the Atkinson with $\varepsilon>1$. The Atkinson measure with $\varepsilon=2$ measure will therefore yield very similar results.

Before turning to the data and the results, it is important to briefly discuss the most important differences between the measures. ${ }^{18}$ Apart from the penalty applied to inequality, the two Gini-based measures differ quite fundamentally from the two Atkinson measures (and thus the Ahluwalia and Chenery measures) in ways that are important to consider. First, the two sets of measures respond differently to equal-sized income transfers at different points in the income distribution. While all measures are consistent with the Dalton principle of transfers, the Atkinson measures obey what has been called 'transfer sensitivity', which means that an equal sized transfer will have a larger impact on inequality (and thus on welfare) if it happens among the poorer sections of the income distribution than if it happens among richer sections (Sen, 1997). ${ }^{19}$ Most would agree that this is a desirable property. In contrast, the largest impact of an equal-sized transfer using the Gini coefficient will be among the mode of the income distribution, i.e. among middle income groups as these transfers will have the largest impact on the rank of the people affected by the transfer and thus the weights attached to their incomes (see Atkinson, 1970; Blackorby and Donaldson, 1978). While there is some justification for this (if income comparisons with others are very important, clearly shifts in income which have a large impact on the ranking should be weighed heavily), most analysts see this as a rather undesirably property of the Gini-based measures (e.g. Atkinson, 1970). Second, the Atkinson measures are sub-group consistent and thus imply that any increase in the income of a subgroup (or a reduction in inequality of that subgroup) will, ceteris paribus, raise aggregate welfare. In contrast, an increase of income accruing to the richest could actually lower aggregate welfare in the Gini-based measures as the increase in mean income can be more than off-set by the increase in inequality. ${ }^{20}$ Some see this as an argument in favor of the Gini-based measures (e.g. Sen, 1997; Dagum, 1990), others see subgroup consistency as a valuable property. For our purposes it will suffice to note that the Gini-based measures penalize inequality more if middle income groups are hurt the most, while the Atkinson measure will penalize more if the poorest are hurt the most by it. Which measure is ultimately a better indicator of welfare is left for the reader to decide.

We will use these measures in different ways. First, we will simply see how much the incorporation of inequality reduces our impression of aggregate well-being. We will therefore present data on how much well-being is reduced in a country at a point in time by the amount of inequality that is present. This can be achieved by simply presenting the ratio of inequality-adjusted income to per capita income. Second, we will examine to what extent the incorporation of inequality changes the ranking of countries. These applications will be used across countries as well as in an intertemporal analysis, where we will look at the years 1960, 1970, 1980, 1990, and 1998. Furthermore, we will study to what extent the inclusion of inequality in the well-being measure will affect our impression

\footnotetext{
${ }^{18}$ For a more extensive discussion of these issues, refer to Atkinson (1970), Blackorby and Donaldson (1978), and Dagum (1990).

${ }^{19}$ The Dalton principle of transfers says that the value of an inequality measure must fall by a transfer from a richer person to a poorer person which does not reverse their position in the income ranking.

${ }^{20}$ See Dagum (1990) for examples. This difference only appears if inequality is much more extreme than the types of inequality existing in today's world.
} 
of changes in well-being in selected countries. Finally, the global analysis concentrates on the years 1970, 1980, 1990, and 1998 and tries to answer the question, how global welfare changed during this period.

\section{The Data}

For both components of the measures, data on mean income and inequality, there are several options. Our main source for data on inequality is the World Income Inequality Database version 1.0 (WIID, 2000), which provides more than 5.000 Gini coefficients and associated distributions for 151 countries. The main sources used for assembling the data set were Deininger-Squire data (Deininger and Squire, 1996), Luxembourg Income Study (LIS, 2000), TransMonee Project (TransMonee, 1999) as well as other research studies and information provided by various Central Statistical Offices. To get recent data for developing countries we also make use of Gini coefficients and income shares provided by the World Bank's Poverty Monitor (WB, 2002). In WIID all observations are classified as either 'reliable' or 'less reliable'. We only use observations which are categorized as 'reliable' and represent the entire population of a country. ${ }^{21}$ With respect to the income concept used we concentrate on gross or net income, or on expenditures. Regarding the unit of income recipient we consider data based on person (or household per capita), or households. Only for few countries we have to rely on data that either have been adjusted for household composition using an equivalence scale or where the income concept used and the reference unit are unknown. ${ }^{22}$ In case, several Gini coefficients with associated distributions were available for a particular country at a particular point in time, those observations were preferably chosen which allowed to have inequality data based on the same or similar specification across time.

Ideally, one would want to at least ensure that the indicators used are based on a consistent definition of income and reference unit both across countries and time. ${ }^{23}$ Pursuing this strategy would result in only a small number of countries and not allow a meaningful international analysis. While in the main analysis we therefore have to contend with differing income concepts and reference units, in the sensitivity analysis, we try to generate consistent data by making suitable adjustments to base all data on unequivalized gross income per person.

Although WIID is probably the most comprehensive source on data on inequality, data for the early years in our analysis are rare and we had to make some adjustments. In case there is no Gini coefficient and associated income shares for the particular point in time, we used the nearest available data for our calculations. Despite these adjustments our samples of countries for which we can calculate all measures are still quite limited. Table 1 shows the different years of available data on income distribution we have chosen

\footnotetext{
${ }^{21}$ Interestingly, it happens that data classified as 'not accepted' in the Deininger-Squire data set, since they are based on either no consistent source (cs) or unknown primary source (ps), are part of the 'reliable data set' in WIID. The opposite, that data belonging to the quality data set in Deininger-Squire data but are categorised as 'not reliable' in WIID, is also possible.

${ }^{22}$ For a discussion of the use of equivalence scales, please refer to Atkinson, Rainwater, and Smeeding (1995), Deaton (1997), and Ayala, Martinez, and Ruiz-Huerta (2001).

${ }^{23}$ Even if Gini coefficients are based on the same definition of income and economic unit they might not be comparable across countries, because of differences in sample methods, quality of surveys etc. (see WIID, 2000).
} 
for the years 1960-1998. The greatest concessions we had to make are for less developed countries like Pakistan, Panama and Chile in 1960, or for Nepal, Indonesia and Singapore in 1970. But also for developed countries like Finland in 1960 and 1970, or Belgium and Italy in 1970 major amendments have been necessary. For 1998, we use the latest available income distribution estimate which in a few cases date as far back as 1990 or 1991, but in most cases comes from the period 1993 to $1997 .^{24}$

Regarding income data one could concentrate on per capita income, per capita disposable income, or per capita consumption. To make our analysis comparable to international comparisons of per capita income and to get the largest possible sample, we rely on per capita gross national product as presented in the national accounts as the income concept used. ${ }^{25}$ For the calculation of the well-being measures we make use of purchasing power adjusted income data provided by the Penn World Table (PWT), versions 6.0 and 5.6 (Heston, Summers, and Aten, 2001; Summers and Heston, 1991). ${ }^{26}$ In addition, we present data on GNP per capita based on official exchange rates from the World Bank for all years as well as the World Bank's purchasing power adjusted income data for the years 1980, 1990, and 1998 (WDI, 1999, 2001, 2002) for comparison. ${ }^{27}$

In our sensitivity analyses, we replace the data used with alternative estimates which either differ in the definition of income and/or reference unit or were provided by another data source. Moreover, we estimate fixed effects panel regressions to try to address the inconsistent treatment of the reference unit and the income concept, using similar procedures as used by Dollar and Kraay (2000) and Lundberg and Squire (1999). Using the regression-based adjustments, all observations are based on gross income per person. ${ }^{28}$

For calculation of global well-being and changes thereof between 1970 and 1998, we start by using a sub sample which consists of 72 countries that represent 81 per cent percent of the world population in 1998. In order to reach such coverage and include some of the populous and high population growth African and Middle Eastern countries, we had to assume in some cases that income inequality remained stable throughout the period studied and only income growth changed, as we have more data on the latter than the former. ${ }^{29}$ However, our main analysis disregards many of the formerly socialist countries since the PWT do not allow to calculate PPP adjusted per capita income for this group of

\footnotetext{
${ }^{24}$ In nearly all cases, we use the exact year for the income estimate under the (implicit) assumption that changes in income distribution between adjacent years are typically smaller than changes in mean income. Given positive average real income growth present in almost all countries which would bias income comparisons from different years, this assumption appears reasonable.

${ }^{25}$ Gross national product should better capture welfare of the population than gross domestic product as the former includes earnings from abroad and excludes earnings by foreigners.

${ }^{26}$ The PWT 6.0 series we deal with is real per capita GDP, chain method (1996 prices) which is turned to GNP per capita using a series that relates current GNP to GDP. This series is only included in version 5.6 and covers the period 1970-1992 for most countries. For the years 1960 and 1998 we adopt numbers reported for the most adjacent years. Since for the vast majority of countries, GNP and GDP are of similar magnitude and country specific ratios of both income measures are relatively constant over time, these manipulations should not cause major problems.

${ }^{27}$ The World Bank data have been converted to 1996 prices using the US GDP deflator (WDI, 2002), since 1996 is the base year used in the PWT 6.0.

${ }^{28}$ We have refined the regressions to take note of criticisms made by Atkinson and Brandolini (2001) regarding such regression-based adjustments. In particular, we take account of the possibility that the difference between gross and net income may be larger in OECD countries.

${ }^{29}$ This way, we included all countries shown in Table 1 with at least two observations on inequality between 1970 and 1998, except for Bulgaria (no income data in 1970 and 1980 available) and Sierra Leone (civil war in the early 1990's probably disrupted (economic) life seriously). The assumption of stability of
} 
countries. Since many of them experienced a considerable worsening in income inequality during the transition period (Milanovic, 1998; Gruen and Klasen, 2001), ignoring them in a global analysis of well-being may yield flawed results. Therefore, we expand our sample by 15 eastern European countries and successor states of the Soviet Union, covering now 86 per cent of the world population, and make a second analysis of global well-being for the years 1988 and 1988 by using GNI per capita in PPP terms provided by WDI (2002). For both samples we calculated average income per quintile for each country, sorted them in ascending order to generate global income quintiles, and then calculated average incomes of these world quintiles based on the population-weighted country quintiles contained in each world quintile. ${ }^{30}$ We thus arrive at average income per 'world quintile' which we applied to the Atkinson measure with $\varepsilon=1$ and $\varepsilon=2$.

\section{International Analysis}

Table 2 presents the analysis for 1960 based on the six measures used. The first two measures are per capita income, using exchange rates and PPP, respectively. The next two are the Atkinson measure with $\varepsilon=1$ and the Sen measure, exhibiting a comparatively 'mild' well-being penalty for inequality. The last two are the Atkinson $(\varepsilon=2)$ and the Dagum measures with a more heavy implied well-being penalty for inequality. The analysis is restricted to only 43 countries. Since they cover a wide spectrum of incomes, big changes in ranks can only happen when there are very drastic differences between the measures.

Well-being, as estimated by our measures, falls drastically when considering inequality. Using the Atkinson $(\varepsilon=1)$ or Sen measure, well-being falls by about 10-65 per cent, and by 70 (Brazil and Mexico) to nearly 80 per cent (Gabon) in the Atkinson $(\varepsilon=2$ ) and Dagum measure. Existing inequality thus leads to fairly major reduction in measured well-being in all the countries considered.

As expected from the discussion of inequality measures above, there are some differences in the extent of 'penalty' for inequality, depending on the measure used. This is to be expected as the Gini-based measures give more emphasis to inequality in the middle income groups, while the Atkinson measure places more weight on inequality among the poorest groups. For example, Pakistan gets penalized less by the Atkinson $(\varepsilon=2)$ measure than the Sen measure, while the reverse is the case for the Philippines. The reason is that in the Philippines the poorest do particularly badly and thus get a heavy penalty in the Atkinson measure, while in Pakistan the middle income groups do relatively worse, which attracts the higher penalty in the Gini-based measure.

In 1960, no assessment of inequality can dislodge the US from the highest rank in all measures, and nothing can prevent Tanzania from being at the bottom of the list for all indicators. Nevertheless, there are a range of interesting changes. First, there is a considerable difference between the ranks using exchange rate and PPP, suggesting the presence

income distribution is, especially when compared to huge variations and changes in income growth levels, reasonable as will be shown below and as has been found by others (e.g. Deininger and Squire, 1998; Lundberg and Squire, 1999). Of the world's 40 most populous countries in 1998, we include all except Russia, Germany, Vietnam, Iran, Ukraine, Democratic Republic of Congo, Myanmar, Argentina, Sudan, Afghanistan, and Uzbekistan.

${ }^{30}$ When a country quintile straddles the line between two world quintiles, we allocated the country quintile proportionately to ensure that the world quintiles contain equal population numbers. 
of over- and undervalued exchange rates. As expected, the discrepancy is larger among poorer countries, related to the undervaluation of the non-traded sectors. Second, there are a number of interesting rank reversals when inequality is progressively being considered. For example, Bangladesh and Madagascar trade places between the pure income and the broader well-being measures. In the two income measures Madagascar is four ranks ahead; in the last two columns, Bangladesh is five ranks ahead. ${ }^{31}$ A similar reversal occurs, somewhat surprisingly, between Britain and Sweden. Sweden is ahead in the pure income measures, while Britain is ahead in measures that also consider distribution; in fact, it mostly occupies the second highest spot in this list. This suggests that the very low inequality in Sweden was not already present in the 1960s, and the rise of Britain reminds us that Britain was among the more equal countries in Europe in $1960 .{ }^{32}$

Table 3 shows our rankings for 48 countries in 1970. Again there are large differences between exchange rate based estimates of real incomes and PPP estimates, with the discrepancy being largest among poorer countries. Considering inequality continues to reduce well-being drastically. Once again, Brazil is one of the countries that lose most: Well-being using the Dagum measure is 73 per cent below the level it would be if its per capita income were equally distributed. The US remains on top in all measures except the exchange rate adjusted income per capita measure, arguably the least reliable indicator of well-being. At the bottom Nepal, Indonesia, and Sierra Leone vie for the worst spot. Some more dramatic reversals in rank occur. Panama falls from number 25 in the exchange rate list to number 41 in Atkinson $(\varepsilon=2)$ measure. Conversely, Sri Lanka rises from 16 ranks below in the first column to one rank above Panama once inequality is considered in the Atkinson $(\varepsilon=2)$ measure. Unequal Brazil trades places with more equal Korea, and now Sweden maintains its rank when inequality is being considered, while Britain's fall in the income rank cannot be completely compensated by its still comparatively low inequality.

Table 4 examines 57 countries for 1980. We now have one more indicator, PPP adjusted income per capita from the World Bank (WDI, 2002), which we place alongside our data from the Penn World Tables. ${ }^{33}$ The comparison suggests that the PPP adjustment is subject to some margin of error. For example, China, India, Pakistan, Bangladesh, Indonesia, Malaysia, Thailand look a lot richer in the PPP adjustment from the Penn World Tables than in the adjustment done by the World Bank while the reverse appears to be the case for many Latin American countries. ${ }^{34}$ Several rank changes happen as a result of these differences in the PPP adjustments.

The inequality-adjusted measures continue to be much lower than the income measure suggesting that inequality continues to have a big impact on well-being. Brazil and

\footnotetext{
${ }^{31}$ Colombia is another country that also falls considerably, once PPP and inequality is considered.

${ }^{32}$ Gottschalk and Smeeding (2000) also report fairly high income inequality in Sweden in the 1960s. In the LIS, Sweden is found to be considerably more equal than Britain. Since the LIS does not go back that far, it is hard to tell whether the reported higher inequality in the 1960s is due to measurement error or true effects. See also sensitivity analysis and Atkinson and Brandolini (2001).

${ }^{33}$ The series used is GNI per capita, PPP in current international dollars. Gross national income is the "sum of value added by all resident producers plus any product taxes (less subsidies) not included in the valuation of output plus net receipts of primary income [...] from abroad" (WDI, 2002). To be comparable to the data from the Penn World Tables we deflated this series to 1996 prices using the US GDP deflator (WDI, 2002).

${ }^{34}$ Compared to earlier versions of the paper, the differences between the measures are of smaller magnitude in general, since the PPP adjusted incomes provided by the Penn World Tables 6.0 are now based on the ICP's benchmark study of 1996. The World Bank's PPP adjustments are grounded on the 1993 benchmark comparison.
} 
Colombia continue to suffer from the largest reductions in well-being which are also now larger than previously, suggesting not only high but worsening inequality. Due to rising inequality and catch-up growth, the US loses its top spot to Belgium in the Atkinson $(\varepsilon=2)$ measure. ${ }^{35}$ Britain still rises in the ranks when inequality is considered. Unequal Brazil and more equal Costa Rica now trade places; Brazil is two ranks ahead in PWT PPP income (column 3), and Costa Rica is one to three places ahead in the inequalityadjusted measures. Bangladesh, on the other hand, no longer improves its position as much as before. ${ }^{36}$

Table 5 examines the per capita income and well-being in 70 countries in 1990. The differences between the PWT and the World Bank PPP adjustments remain considerable, but consistent in the sense that the differences in assessment in 1990 are largely the same as for 1980. Well-being continues to be much lower than before; by and large, the reduction appears to be similar to previous decades suggesting no general worsening (or improvement) in income distribution.

Regarding rank reversals, Brazil and South Africa, two of the world's most unequal countries, get surpassed in the Atkinson measure $(\varepsilon=2)$ by Indonesia, a country 25 and 30 ranks, respectively, below in the income ranking with less than half the PPP income per capita when compared to Brazil. That is to say, Brazil could generate the same level of well-being with only half the income, if that income was as evenly distributed as it is Indonesia.

Low levels of income and sizeable income inequality assure that many African countries land at the bottom end in all measures. At the other end of the spectrum, the US only retains the second spot in the PPP-adjusted income measures and the mildly penalizing inequality adjusted measures. In the Dagum measure it is surpassed by Canada and Luxembourg and, in the Atkinson $(\varepsilon=2)$ measure, additionally by Belgium and the Netherlands. This fall in ranks of the US is mostly due to rising inequality there, compared to the other countries (rather than differences in average income growth). Clearly, people in the US are paying a price in terms of well-being due to the higher inequality there and other countries do not suffer from the same problem (see Klasen (1994) and also below). ${ }^{37}$ Also in Britain, higher inequality ensures that Britain no longer rises in ranks and even falls in some measures once inequality is considered (see below).

Table 6 shows the well-being measures for 71 countries in 1998. At the bottom end, we again find mostly African countries. Indonesia still improves in ranks and is ahead of Peru in the Dagum and Atkinson $(\varepsilon=2)$ measures. Similarly, poorer Bulgaria and richer Mexico trade places in two measures which also consider inequality. At the top end, the US again leads the pack, with the exception of the first ranking where official exchanged rates are used, since they experienced a substantial increase in income per capita and a

\footnotetext{
${ }^{35}$ The US loses especially in the Atkinson $(\varepsilon=2)$ measure as the poorest are particularly badly off in the US. See also Gottschalk and Smeeding (2000).

${ }^{36}$ This is due to somewhat higher observed inequality in 1980, which falls again in the late 1980s and early 1990s. To what extent this data point is an aberration, is difficult to tell.

${ }^{37}$ Please note that these results differ from Ayala, Martinez, and Ruiz-Huerta (2001) which, based on micro data, find that the US is surpassed only by Belgium in the Atkinson $(\varepsilon=2)$ measure, while Canada and Sweden remain considerably worse off. The difference in findings is probably mainly due to the use of the mean (gross) income variable based on national accounts used here, while in Ayala, Martinez, and Ruiz-Huerta (2001) mean income refers to disposable income based on adjusted micro data. Other sources of differences could be the different PPP adjustments used (PWT versus OECD PPP adjustments), and differences in the Gini coefficients.
} 
comparatively small change in income inequality compared with $1990 .{ }^{38}$ Rising inequality in Canada is ensuring that it is falling further behind, being surpassed by seven other OECD countries in the Atkinson $(\varepsilon=2)$ measure.

It is hard to summarize the many particular findings from this discussion. But a few points are worth noting. First, real income comparisons based on official exchange rates give a very misleading impression of well-being. In particular, they systematically understate well-being in developing countries. At the same time, there are discrepancies between the two sets of available PPP estimates. Second, consideration of inequality has a large impact on well-being. Well-being falls by 15-75 per cent once we consider inequality. The comparison of welfare levels between Indonesia and Brazil in Figure 1 is informative here. Relying on unadjusted income measures, Brazil is far ahead of Indonesia in all years, but once inequality is considered as well, Brazil's welfare levels drop sharply and in 1998 Indonesia has not only closed the gap but, according to the newly introduced Atkinson measure with $\varepsilon=5$ reached a slightly higher welfare level than Brazil. Third, large differences in inequality between countries lead to very large changes in rank. Brazil's drop in rank is a very dramatic illustration of this. Fourth, changes in inequality have an important impact in some countries, most notably the US and Britain. This is nicely illustrated in Figure 2 which examines the welfare levels for the US and Canada between 1970 and 1990. While the slopes of the curves for the US become steeper when going from 1970 to 1990 thereby indicating rising inequality which leads to lower welfare levels, Canada experiences declining inequality and is thus able, according to some measures, to reach a higher welfare level than the US in $1990 .{ }^{39}$ Fifth, the combination of income growth as well as levels and changes in inequality together can lead to very large differences in changes in well-being. The comparison between Sri Lanka and Peru is instructive here (see Figure 3). Sri Lanka combines comparatively low inequality with steady growth, Peru experienced considerable fluctuations in its mean income with relatively high inequality. In 1998, despite being still poorer in income than Peru, Sri Lanka has already a higher welfare level in the Atkinson $(\varepsilon=2)$ measure and adds to this lead if $\varepsilon=5$ is assumed.

To assess whether these findings are due to peculiarities and inconsistencies of the data chosen, we present a sensitivity analysis in the following.

\section{Sensitivity Analysis}

The robustness of our results is verified with the help of two different approaches. Firstly, we simply replace the data on income distribution used in the original analysis. For those countries we have alternative data available which are either based on different income concepts and/or reference units or come from other data sources, we replace Gini coefficients and income shares, calculate the measures, rank the countries again and compare the results with those obtained from the first analysis. ${ }^{40}$

\footnotetext{
${ }^{38}$ This statement seems to be justified, even although the data on income distribution used in 1998 originally stems from 1991, since this is also the case for other OECD countries like Canada, Great Britain, Italy, Netherlands, and Norway.

${ }^{39}$ Interestingly, Canada, despite its smaller income, also regularly surpasses the US in the Human Development Index calculated by the United Nations Development Programme UNDP (2002).

${ }^{40}$ We restrict this replacing to alternative data which are based on the same year (plus/minus one year) as was used in the main analysis.
} 
Table 7 shows the Gini coefficients and their alternatives, what income concepts and recipient units they are based upon as well as the resulting changes in rankings. The simultaneous replacement approach leads mainly to no or only small changes in ranking. However, in some cases major changes take place. The alternative Gini coefficient used for Jamaica in 1960 exceeds the one originally used by only 1.7 percentage points, which leads to only little changes in ranking when focussing on the Gini based measures. However, the income shares (which are not reported here) partly change considerably, leaving the poorest 20 per cent with only half the income and increasing the share of income going to the richest 20 per cent of population by almost 50 per cent. The Atkinson measures answer these dramatic changes with notably lower ranks.

Turning to the year 1980, Canada and Norway experienced significant changes in ranking. For both countries the alternative Gini coefficients were taken from LIS (2000) and are based on the same specifications as the ones used in the original analysis. However, the Gini coefficients itself differ considerably, thereby leading to changes up to 8 ranks. Data on inequality provided by the Luxembourg Income Study are derived from micro data sets and undergo different strategies of top and bottom coding - both may contribute to the existing differences.

Mexico in 1990 is another example of the bandwidth of inequality data available for one particular point in time. Both Gini coefficients were provided by Deininger and Squire (1996) but belong to different quality classifications. The main difference between the two indices is the income share going to the richest 20 per cent of population, which amounts to 59.3 per cent in the first distribution but is declining to 53.6 per cent in the one used alternatively. Consequently, distribution of income is more equal according to the alternative data and especially the measures that penalize the existing degree of inequality more rank Mexico up to 6 positions higher.

In a second kind of sensitivity analysis, we use a regression-based approach to deal with the inconsistencies in terms of the income concepts and reference units used. We expand our sample by adding data of countries not considered in the main analysis but which are part of the reliable set in WIID (2000). This enables us to get several observations per country at the same time which should improve our ability to identify the reference unit and income definition effects. In particular, we regress the Gini coefficients available on the income definition (expenditure, net income, unknown income, or gross income, the excluded category), and the reference unit considered (household, family, unknown, equivalized, or person, the excluded category). Following suggestions from Atkinson and Brandolini (2001), we include dummy variables for Deininger-Squire data labelled as 'cs' (no consistent source) and 'ps' (primary source unknown).

Regression 1 in Table 8 shows that indeed the income definition and the choice of reference unit do matter. Expenditure-based and net-income or equivalized Gini coefficients are typically lower, while household-based Gini coefficients appear to be higher. ${ }^{41}$ The interaction term net income and OECD countries in the second regression shows that the difference between gross and net income is largely a phenomenon of OECD countries, as one would expect (Atkinson and Brandolini, 2001).

\footnotetext{
${ }^{41}$ The somewhat surprising result about household-based Gini coefficients was also found by Lundberg and Squire (1999). Note that the regressions here have considerably higher explanatory power (as measured by the R-squared) as the ones used by Dollar and Kraay (2000) and Lundberg and Squire (1999).
} 
We then adjust the Gini coefficients based on the regression results from the first estimation and thereby base all these adjusted Gini coefficients on the omitted categories, i.e. gross income per person. This way we should have dealt with the most glaring inconsistencies, although further adjustments are surely possible (Atkinson and Brandolini, 2001).

How do the results change if one uses these adjusted Gini coefficients for the calculation of the Gini based measures? Table 9 shows that generally the results do not change greatly. Using the Sen measure, the vast majority of rankings remain the same or change only by one position. Regarding the Dagum measure, more significant variations happen, but again there is more persistence than change. In 1998, the year when most changes occur due to the adjusted Gini coefficients, less than 15 per cent of rank changes were by more than one position. Moreover, most of the dramatic rank reversals and changes discussed earlier still hold. ${ }^{42}$

These sensitivity analyses suggest that few of the basic results on the large absolute impact of inequality and the change in ranks as a result of it reported are meaningfully affected by using different data sets. However, quite a number of individual rankings are affected so that analyses that focus on these smaller differences, particularly among OECD countries, should use more consistent data sources rather than rely on the rather heterogeneous information (Ayala, Martinez, and Ruiz-Huerta, 2001).

\section{Comparisons Across Time}

The discussion in section 5 has already suggested that in some countries inequality has changed considerably. At the same time, it appears that there is also a great deal of stability in inequality measures which has also been found by Deininger and Squire (1998) and Lundberg and Squire (1999). Most countries either seem to improve or worsen in rank at a point in time when inequality is considered, with this relationship not changing much over time. In this section we examine this question a bit more closely.

A first impression can be gleaned from Table 10 which shows average Gini coefficients from the 1960s to the 1990s. What emerges is a great deal of stability. The average Gini, whether raw or adjusted based on regression 1 in Table 8, does not appear to have changed a lot (see also Deininger and Squire, 1998; Lundberg and Squire, 1999). ${ }^{43}$ This average could, however, mask some variation. Therefore we specify fixed and random effects regressions to examine this question closer. First, we want to see whether, controlling for country-specific fixed and random effects, there are temporal trends in inequality. In Table 11 specifications (1) and (2) show the results from the fixed and random effects regressions. ${ }^{44}$ While the general impression of great stability is supported, results suggest that, when compared to the 1990s, inequality was significantly higher in the 1960s,

\footnotetext{
${ }^{42}$ For example, while Brazil and Indonesia still move towards similar welfare levels once inequality is considered in the measurement, Brazil remains more ranks ahead in the inequality adjusted welfare measures. This is mostly due to the fact that the Indonesian data are based on expenditures while the Brazil data are based on gross incomes. Similarly, Britain rises less in the early years considered and it falls more in the later years once the adjusted Gini is used, since an equivalence scale was applied to the originally used data.

${ }^{43}$ The small observed changes could be due to compositional changes.

${ }^{44}$ The Hausman test suggests that random effects would be preferable to use, although the results do not differ much.
} 
and significantly lower in the 1980s, but the average differences were not very large in magnitude. ${ }^{45}$

The last two specifications are fixed effects regressions testing for an intertemporal Kuznets curve, i.e. the suggestion that as countries go through the process of development, inequality first worsens and then improves again. The results are quite clear here. There is not even the smallest hint for such an inverse U relationship that would hold systematically across all countries (see also Deininger and Squire, 1998; Lundberg and Squire, 1999). In fact, specification (4) rather suggests the opposite, namely a U shaped relationship, even though it is not a very distinct curve. Thus, on average, there do not seem to be systematic trends in income distribution that relate either to temporal trends or to trends in income. It does not appear that inequality within countries is rising or falling systematically. For our study of well-being, this is a significant finding since it basically tells us that assessments of changes in well-being will not change very much for most countries if we switch from an income growth rate to a measure that growth rates in the distributionsensitive measures.

Figures 4 and 5 plot two typical examples. While Brazil and Indonesia differ greatly with respect to the degree of existing inequality, the income distributions itself did not vary a lot in the last decades. This results in comparatively small differences between an income growth rate and the growth rate of our distribution-adjusted income measures (illustrated by similar height of the first columns of each measure). At the same time, this general stability masks some apparent rises and declines in inequality in those countries. For example, in Brazil inequality appears to have become notably more unequal between 1961 and 1990, which in the sub-period 1981-1989 was accompanied by only moderate income growth leading not only to smaller, but negative growth rates in the inequality adjusted welfare measures, while since 1990 this trend has been reversed. Thus one should not interpret longer-term stability as the absence of any developments in sub-periods (see also Atkinson and Brandolini, 2001). Canada and Finland are two other examples where changes in inequality differed in different time periods (Figures 6 and 7). Finland is particularly notable for the fact that inequality appears to have declined considerably since the 1980s leading to higher changes in well-being once inequality is considered. Finally, the case of China (Figure 8) illustrates that considerable income growth is not automatically associated with a worsening income distribution, although higher inequality in the 1990s let the inequality adjusted growth rates become smaller.

It thus appears that the processes that led to increases in inequality in some rich countries (notably the US and Britain) are not global processes or even processes that affect all industrialized countries the same. ${ }^{46}$ Despite some rhetoric to the contrary, all rich countries do not appear to be condemned by global forces or other processes to face ever-rising inequality. Although a careful investigation of this issue goes beyond the scope of this paper, the differences in experience suggest that the role of economic policy in generating and combating income inequality is quite considerable (see also Atkinson, 1997; Aghion and Williamson, 1998).

Despite this general rule, there are some notable exceptions and it is important to emphasize that in some countries assessment of income growth seriously bias our view of

\footnotetext{
${ }^{45}$ These results are robust to using the adjusted Gini coefficients.

${ }^{46}$ Based on the LIS, Gottschalk and Smeeding (2000) find that in the majority of OECD countries, there was some increase in inequality in the 1980s. The timing and the extent differed greatly, however, and it was far from being a universal phenomenon. See also Ayala, Martinez, and Ruiz-Huerta (2001).
} 
changes in well-being. In particular, we will study Britain and the US. ${ }^{47}$ The impact of inequality on changes in well-being in the US was already studied in Klasen (1994). Here the analysis is extended to 2000 and some other measures are considered in addition. Figure 9 shows the basic results. During the 1950s and the 1960s, high annual growth was accompanied by falling inequality which ensures that increases in well-being were considerably above the income growth rate. In contrast, in the 1970s, 1980s, and 1990s, low to moderate income growth was accompanied by sharply rising inequality so that well-being grew by negligible amounts. In fact, it shrank in the 1980s, depending on the measure. ${ }^{48}$

Since economic growth has picked up since 1993 and unemployment is/was at a 30 years low, one may wonder how well-being changed in the so-called 'new economy.' Figure 10 gives an impression. Income growth since 1993 has been still somewhat below the high growth rates of the 1960s, and inequality continues to worsen (although at a much slower pace) in the 1990s. This time, it is more due to greater income increases among the rich, rather than deteriorations among the poor which was the case in the 1980s. This rising inequality means that well-being in the 'New Economy' is growing considerably more slowly than in the much-maligned 1960s where high growth was accompanied by falling inequality.

The story for Britain looks much the same (Figure 11). Based on the inequality series produced by the Institute of Fiscal Studies (IFS), in the 1960s and the 1970s, moderate income growth was accompanied by falling inequality thus leading to sharper increases in well-being. In the 1980s, moderate income growth translated into stagnation of well-being once the sharply rising inequality is accounted for (see also Atkinson, 1997).

\section{Global Well-Being and Inequality}

As is well-known, global inequality is more of a result of inequality between nations than inequality within nations (Anand, 1993; Berry, Bourguignon, and Morrison, 1991; Milanovic, 2002). The richest 20 per cent of the world consume some 70-80 per cent of world income (depending on the calculation and the countries included), leaving some 2-3 per cent to the poorest 20 per cent, which is far larger than the discrepancy between the rich and poor in any one country (UNDP, 1999; Milanovic, 2002). As a result, we would expect that consideration of this inequality between nations should have a considerable impact on our measures of well-being. Figure 12, based on 'our world' which captures some 81 per cent of the population in 1998 but leaves out quite a few of the poorest as well as many transition countries, shows that it does indeed. Using the Atkinson measures, we find that world well-being is less than half if we use $\varepsilon=1$ and only about a quarter if we use $\varepsilon=2$ for all years considered. This is to say that 'our world' would be as well off as it is currently if it only had half or a quarter its income and distributed that evenly.

\footnotetext{
${ }^{47}$ Many formerly socialist countries experienced sharp increases in inequality during the period of transition which was also accompanied by negative income growth. In Kyrgyz Republic and Ukraine this resulted in dramatic welfare losses up to 75 per cent for the period 1988-1995 according to Atkinson $(\varepsilon=2)$ and Dagum measures. See also Gruen and Klasen (2001).

${ }^{48}$ Also here, one can nicely see the difference between the Gini-based measures and the Atkinson measures. The poorest did particularly badly in the 1980s and the Atkinson measure with $\varepsilon=2$ shows a deterioration in well-being.
} 
Including the missing poor countries would lead to even more dramatic reductions in well-being. Global inequality is not just a political, economic, and social problem, it is a welfare problem as it reduces aggregate global well-being considerably.

Figures 12 and 13 also show that global inequality in our restricted world does not seem to have increased a great deal over the last 30 years. While it was relatively stable between 1970 and 1980, it decreased quite remarkably since then. The growth of the Atkinson measures far surpasses the growth in mean global income, particularly in the 1980s. This is mostly due to high and fairly evenly spread per capita growth in China and India, as well as high growth in other dynamic Asian economies which push up income growth of the poorest three quintiles of the world income distribution, as Figure 12 shows (see also Schultz, 1998).

Income growth and changing distribution could also result in a considerable degree of income mobility. Table 12 illustrates how many country quintiles fall into the particular global quintiles and what changes took place between 1970 and 1998. According to the admittedly rather crude measure, there seems to be a great deal of stability, since 203 out of the 360 country quintiles belong to the same world quintile in both years. ${ }^{49}$ Furthermore, this stability is very much concentrated at the lower and upper tail of the world income distribution, which was already found by Quah (1993). In case of the richest global quintile this finding can be attributed to many OECD economies, which, except for their poorest country quintiles, already succeeded in 1970 to belong entirely to this income group. Turning to the bottom end, most African countries considered in this analysis could not drop out of the lowest spots in the global income distribution. ${ }^{50}$ Among the population that managed to move upwards and reached the highest income category in 1998 are the second to fourth quintiles of Korea as well as the poorest three quintiles of Singapore. Similar upward mobility can be observed for Indonesia, China, Sri Lanka, Malaysia, and Thailand, while many African countries like Tanzania, Ethiopia, Uganda, Nigeria, Kenya as well as Bangladesh, Colombia, and Guatemala exhibit downward mobility. In 1998, their country quintiles are found among lower global quintiles than in 1970.

By looking at the results obtained from our expanded sample which considers 15 transition countries in addition, it becomes clear, that the assessment of global inequality and well-being is to some extent driven by sample size, the period considered, and the choice of income data. In this second global analysis, we use PPP adjusted income data provided by the World Bank (WDI, 2002). As is evident from Tables 4-6, the World Bank's calculation assumes that incomes in some of the poorer countries are somewhat lower than in the Penn World Tables, which will lead to higher global inequality. In 1998, global welfare level is of similar magnitude for both samples, with the discrepancy being larger among poorer quintiles. Turning to changes in well-being during the last decade, the two samples tell different stories. As shown in Figure 14, the first four global quintiles of the larger sample still realized positive income growth between 1988 and 1998, but at considerably lower rates. The richest world quintile, however, experienced negative income growth. This somewhat surprising result is largely caused by dramatic income losses that many of the socialist countries had to deal with during the transition period. In 1988, the richest country quintiles of 16 transition countries fall into the fifth world quintile; out of them eight still belong to it in 1998, despite having realized considerably income losses.

\footnotetext{
${ }^{49} \mathrm{In}$ fact, income mobility is much higher, since there is a lot variability within each world quintile.

${ }^{50}$ The increasing number of country quintiles falling into the poorest world quintile is mainly due to the fact, that the second poorest quintile of China could climb into the next income category.
} 
These losses cannot be balanced out by positive income growth in other countries, and the average income for the richest 20 per cent of the world's population considered here is declining. On the other hand, although both the inclusion of transition countries and the use of the World Bank's income data lead to higher inequality at a global level, the trend of declining inequality since the 1980s is not affected, as the growth rates of the Atkinson measures exceed the growth of mean income.

Thus, in line with some other studies (e.g. Schultz, 1998) but in contrast to findings from studies by UNDP (1999) and Milanovic (2002), there has not been a uniform rise in global inequality, nor has there been no mobility of countries up and down the world income distribution. ${ }^{51}$ Including even more of the poorest countries would, however, somewhat temper this assessment as they are likely to have contributed to increasing global inequality and less mobility.

Clearly, global inequality is associated with major reductions in well-being. In fact, the reductions are larger than similar reductions within countries since inter-country inequality is so much larger than intra-country inequality. At the same time, high growth in China and India, where most of the world's poor live, and considerably mobility suggest that we are not necessarily facing a world of rising and ever more rigid global distribution.

\section{Summary and Conclusion}

From a theoretical point of view, the inclusion of income inequality in a measure of wellbeing is well justified. Here, we tried to demonstrate, what impact the various measures have when applied to a rich set of data. Summarizing the multi-faceted results, it firstly can be said that the consideration of the distribution on income affects our assessment of absolute well-being at a country and, even more so, at a global level. Secondly, it frequently alters the ranking of countries drastically. Regarding comparisons across time we found that in some countries the impression of changes in well-being differs when level and changes of inequality are taken into account. Thus, we conclude that it seems worth exploring the linkages between growth, inequality, and well-being further.

The global analysis showed, that the last decades have seen periods, where global inequality was rising and falling, where countries moved upwards and downwards the world income distribution, suggesting that there is scope for economic policy to influence within-country inequality which then also affect global inequality.

Being aware that much of the data we applied were not intended to be used in such examinations, we tried to verify our results. We found that although data on inequality are still not sufficiently consistent neither across time nor across countries, many of the main findings are relatively robust. The late 1990s have seen the evolution of the World Income Inequality Database which provides easy access to indexes and distributions as well as quality ratings thereby enabling us to make a careful choice. Despite these already immense improvements, future developments should be directed at generating consistent and internationally comparable time series on inequality.

\footnotetext{
${ }^{51}$ Milanovic (2002) uses micro data to generate estimates for global inequality in 1988 and 1993 . He finds sharply rising global inequality. The difference between his and our finding is probably due to the choice of time period, the large representation of transition economies in his data set, and the use of mean income figure that is based on micro data and may bear little resemblance with national accounts data used here.
} 


\section{References}

Aghion, P., And J. Williamson (1998): Growth, Inequality, and Globalization. Cambridge University Press.

Ahluwalia, M., And H. Chenery (1974): Redistribution with Growthchap. The Economic Framework. Oxford University Press, London.

Alesina, A., And D. Rodrick (1994): "Distributive Politics and Economic Growth," Quarterly Journal of Economics, 109(2), 465-490.

AnAnd, S. (1993): "Inequality between and within nations," Cambridge, Mimeographed.

Arrow, K. (1963): Social Choice and Individual Values. New Haven: Yale University Press.

Atkinson, A. B. (1970): "On the Measurement of Inequality," Journal of Economic Theory, 2(3), 244-263.

(1997): "Bringing Income Distribution In From The Cold," The Economic Journal, 107(441), 297-321.

Atkinson, A. B., And A. Brandolini (2001): "Promise and Pitfalls in the Use of "Secondary" Data-Sets: Income Inequality in OECD Countries as a Case Study," Journal of Economic Literature, 39(3), 771-799.

Atkinson, A. B., L. Rainwater, and T. Smeeding (1995): Income Distribution in OECD Countries. OECD.

Ayala, L., R. Martinez, and J. Ruiz-Huerta (2001): "The Impact of Unemployment on Inequality and Poverty in OECD Countries," Economics of Transition, 9(2), 417447.

BanerJee, A. (1997): "Policy making in an overconsuming World: Some Finger Exercises," Cambridge, Mimeographed.

Bardhan, A., and S. Klasen (1999): "UNDP's Gender-Related Indices: A Critical Review," World Development, 27(6), 985-1010.

Berry, A., F. Bourguignon, and C. Morrison (1991): Economic Inequality and Povertychap. Global Economic Inequality and Its Trends Since 1950. M.E. Sharpe, Inc., Armonk.

Blackorby, C., And D. Donaldson (1978): "Measures of Relative Equality and Their Meaning in Terms of Social Welfare," Journal of Economic Theory, 18(1), 59-80.

Clarke, G. R. G. (1995): "More Evidence on Income Distribution and Growth," Journal of Development Economics, 47(2), 403-427.

Dagum, C. (1990): "On the Relationship between Income Inequality Measures and Social Welfare Functions," Journal of Econometrics, 43(1-2), 91-102.

Deaton, A. (1997): The Analysis of Household Surveys. Baltimore: The John Hopkins University Press. 
Deininger, K., And L. Squire (1996): "A new Data Set Measuring Income Inequality," The World Bank Economic Review, 10(3), 565-591.

(1998): "New Ways of Looking at Old Issues: Inequality and Growth," Journal of Development Economics, 57(2), 259-287.

Dollar, D., And A. KraAy (2000): "Growth is Good for the Poor," Mimeographed.

EAsterlin, R. (1995): "Will raising the incomes of all increase the happiness of all?," Journal of Economic Behavior and Organisation, 27(1), 35-47.

Gottschalk, P., and T. Smeeding (1997): "Cross-National Comparisons of Earnings and Income Inequality," Journal of Economic Literature, 35(2), 633-687.

- (2000): "Empirical Evidence on Income Inequality in Industrial Countries," Handbook of Income Distribution.

GraAf, J. D. V. (1957): Theoretical Welfare Economics. London: Cambridge University Press.

Gruen, C., And S. Klasen (2001): "Growth, Income Distribution and Well-Being in Transition Countries," Economics of Transition, 9(2), 359-394.

Heston, A., R. Summers, And B. Aten (2001): "Penn World Table Version 6.0," Center for International Comparisons at the University of Pennsylvania (CICUP), http://webhost.bridgew.edu/baten/.

Hill, R. J. (2000): "Measuring Substitution Bias in International Comparisons Based on Additive Purchasing Power Parity Methods," European Economic Review, 44(1), $145-162$.

Hirsch, F. (1977): The Social Limits to Growth. Cambridge: Harvard University Press.

Jenkins, S. P. (1997): "Trends in Real Income in Britain: A Microeconomic Analysis," Empirical Economics, 22(4), 483-500.

Klasen, S. (1994): "Growth and Well-Being: Introducing Distribution-Weighted Growth Rates to Reevaluate U.S. Post-War Economic Performance," Review on Income and Wealth, 40(3), 251-272.

(1999): "Does Gender Inequality Reduce Growth and Development?," Policy Research Working Paper No. 7, Washington, DC: The World Bank.

LIS (2000): "Luxembourg Income Study," http://www.lisproject.org/.

Lundberg, M., and L. Squire (1999): "The Simultaneous Evolution of Growth and Inequality," Mimeographed.

Milanovic, B. (1998): Income, Inequality, and Poverty during Transition from Planned to Market Economy. World Bank.

(2002): "True World Income Distribution, 1988 and 1993: First Calculation based on Household Surveys Alone," The Economic Journal, 112(476), 51-92. 
Osberg, L., And A. Sharpe (2000): "Esimates of an Index of Economic Well-Being for OECD Countries," Mimeographed.

Persson, T., and G. Tabellini (1994): "Is Inequality harmful for Growth," American Economic Review, 84(3), 600-621.

QuAH, D. (1993): "Empirical cross-section dynamics in economic growth," European Economic Review, 37, 426-434.

Ravallion, M. (1997): "Good and Bad Growth: The Human Development Reports," World Development, 25(5), 631-638.

Rawls, J. (1971): A Theory of Justice. Cambridge: Harvard University Press.

Samuelson, P. A. (1947): Foundations of Economic Analysis. Cambridge: Harvard University Press.

Schultz, T. P. (1998): "Inequality in the Distribution of Personal Incomes in the World: How it is Changing and Why," Journal of Population Economics, 11(3), 307-344.

Sen, A. (1973): Collective Choice and Social Welfare. Cambridge: Harvard University Press.

(1982): Choice, Welfare and Measurementchap. Real National Income. Basil Blackwell, Oxford.

(1984): Resources, Values, and Developmentchap. The Welfare Basis of Real Income Comparisons. Cambridge: Harvard University Press.

(1987): Commodities and Capabilities. Cambridge: Harvard University Press.

_ (1997): On Economic Inequality. Oxford: Clarendon Press.

_ (1999): Development as Freedom. Alfred A. Knopf, New York.

SRInivasan, T. N. (1994): "Human Development: A new Paradigm or Reinvention of the Wheel?," American Economic Review, 84(2), 238-243.

Summers, R., And A. Heston (1991): "The Penn World Table (Mark 5): An expanded Set of International Comparisons, 1950-1988," Quarterly Journal of Economics, 106(2), $327-368$.

Transmonee (1999): "Monitoring Social Conditions and Public Policy in Central and Eastern Europe," UNICEF, http://eurochild.gla.ac.uk/Documents/monee/.

UN (1992): "Handbook of the International Comparison Programme," United Nations Publication, Department of Economic and Social Development, Statistical Division.

UNDP (1995): Human Development Report 1995. Oxford University Press, United Nations Development Programme.

(1999): Human Development Report 1999. Oxford University Press, United Nations Development Programme. 
(2002): Human Development Report 2002. Oxford University Press, United Nations Development Programme.

WB (2002): "Global Poverty Monitoring," The World Bank, http://www.worldbank.org/ research/povmonitor/.

WDI (1999): “World Development Indicators 1999," The World Bank.

_ (2001): "World Development Indicators 2001," The World Bank.

_ (2002): "World Development Indicators 2002," The World Bank.

WIID (2000): "World Income Inequality Database Version 1.0," World Institute for Development Economics Research, http://www.wider.unu.edu/wiid/wiid.htm. 


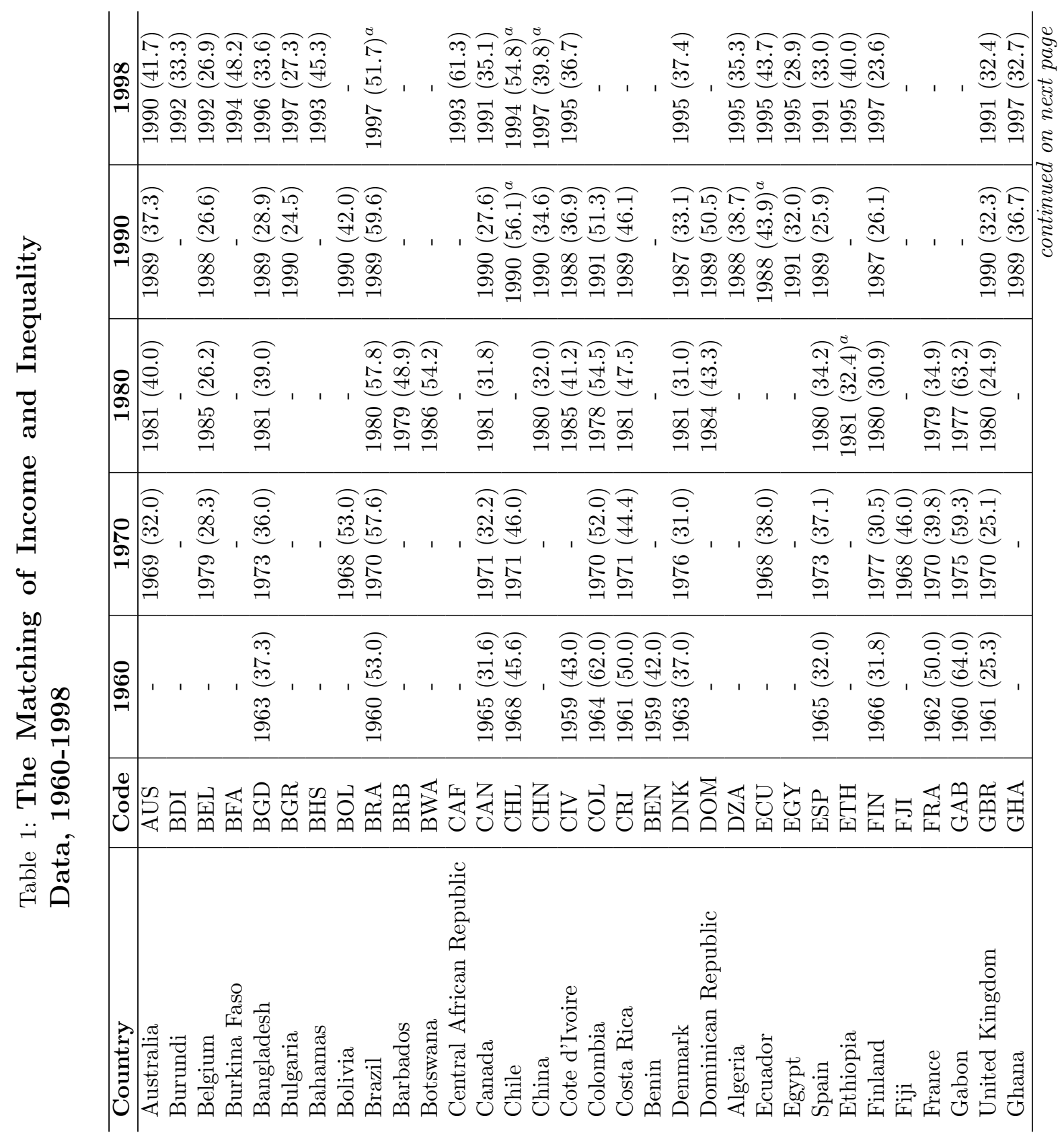




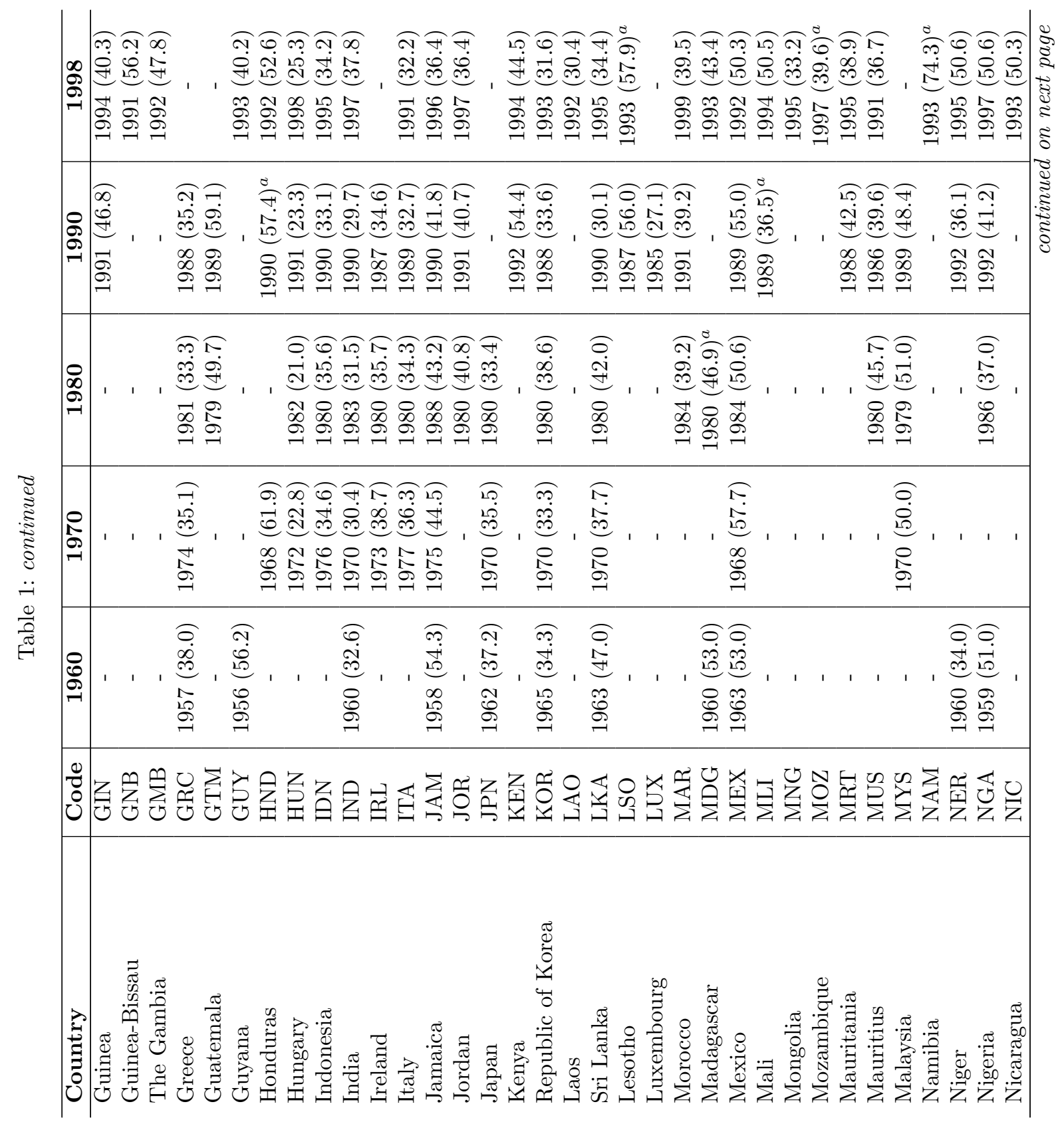




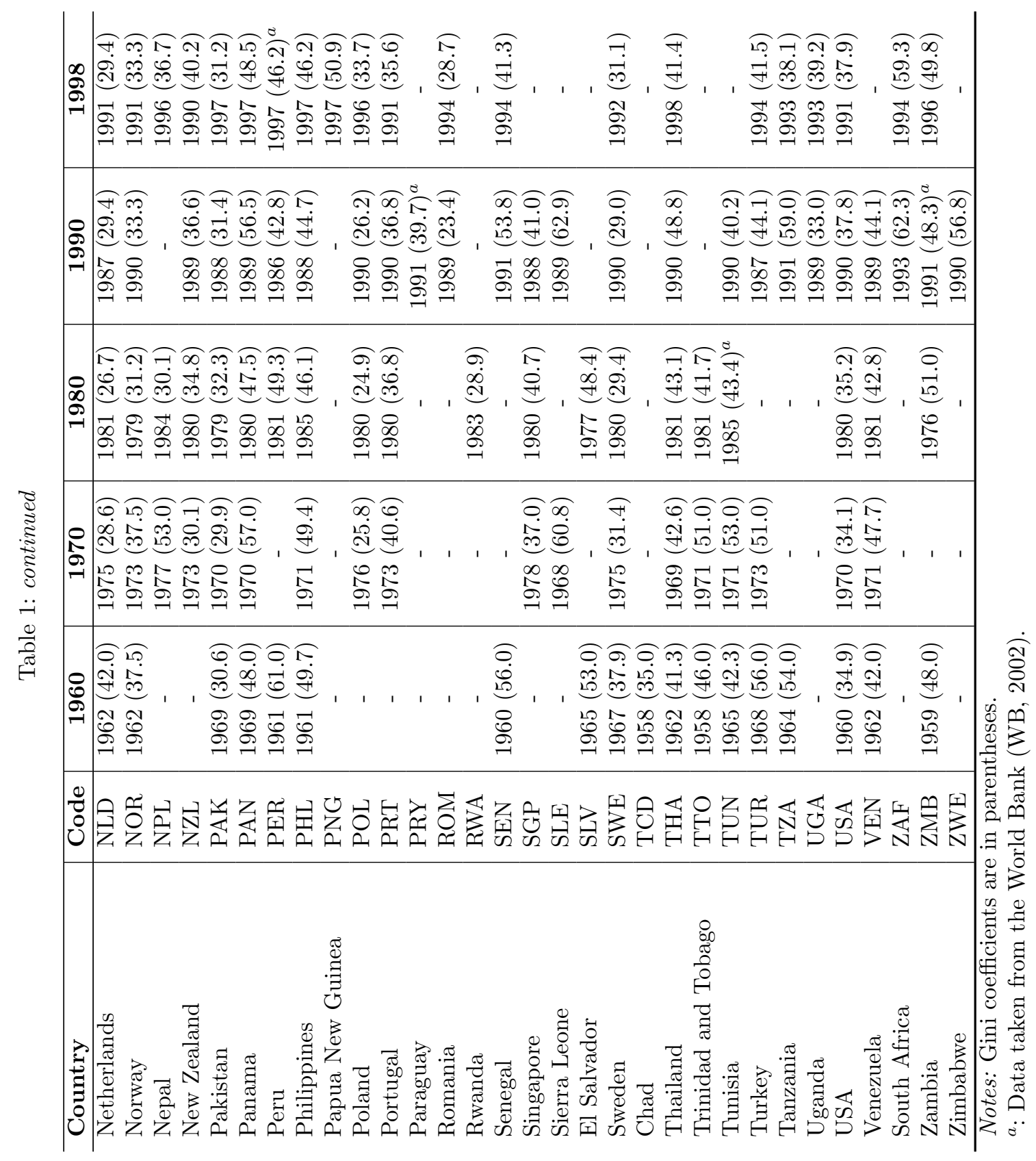




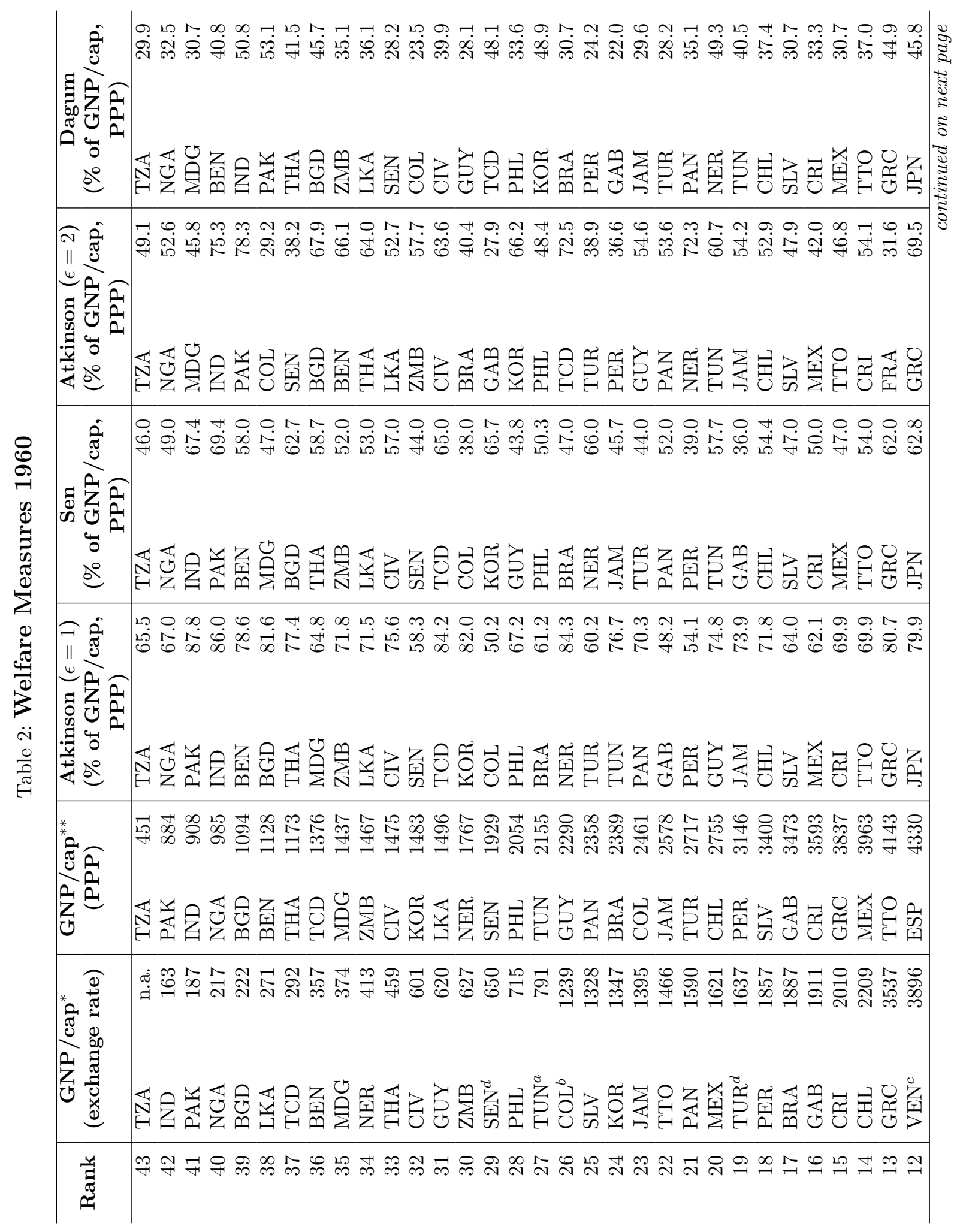




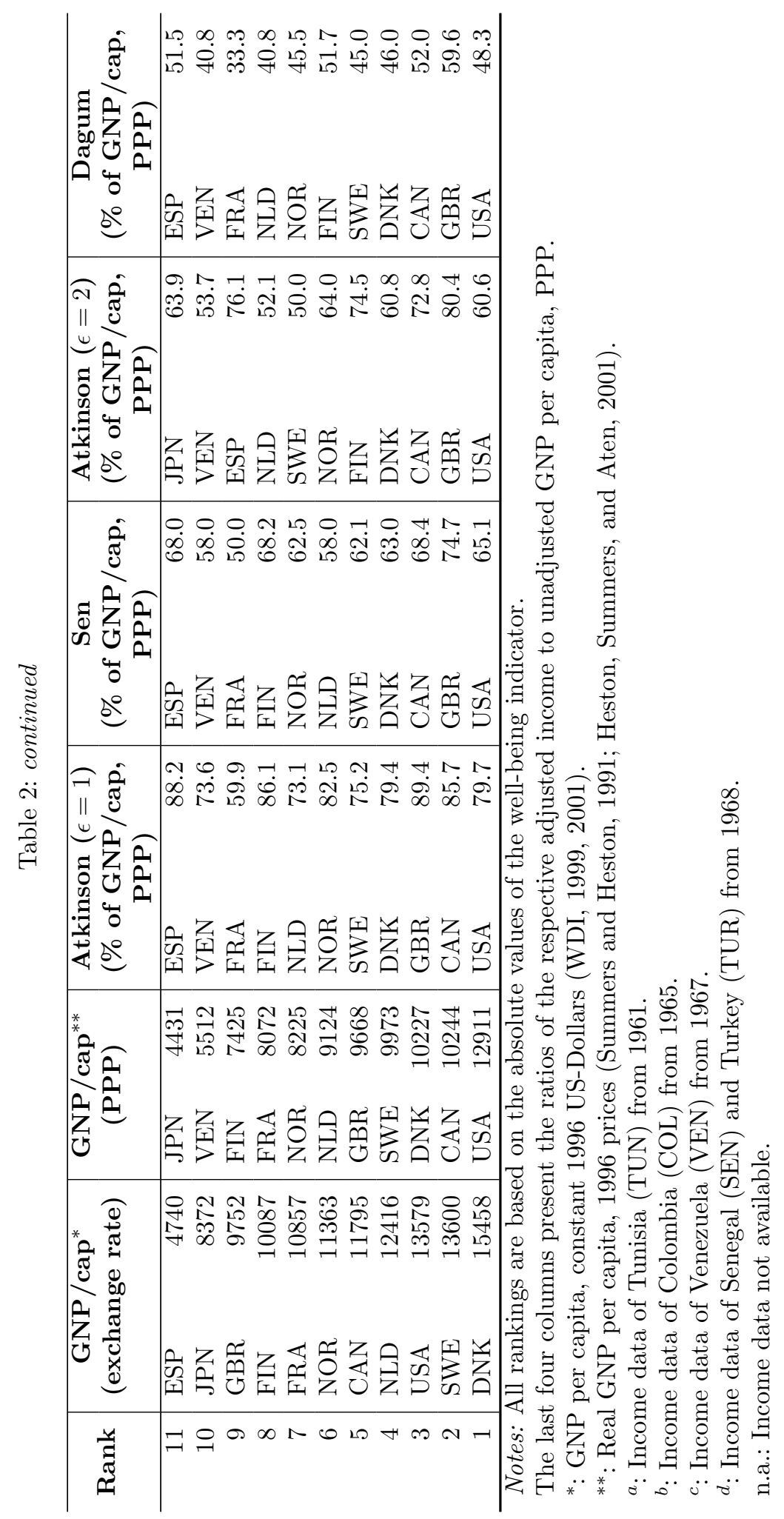




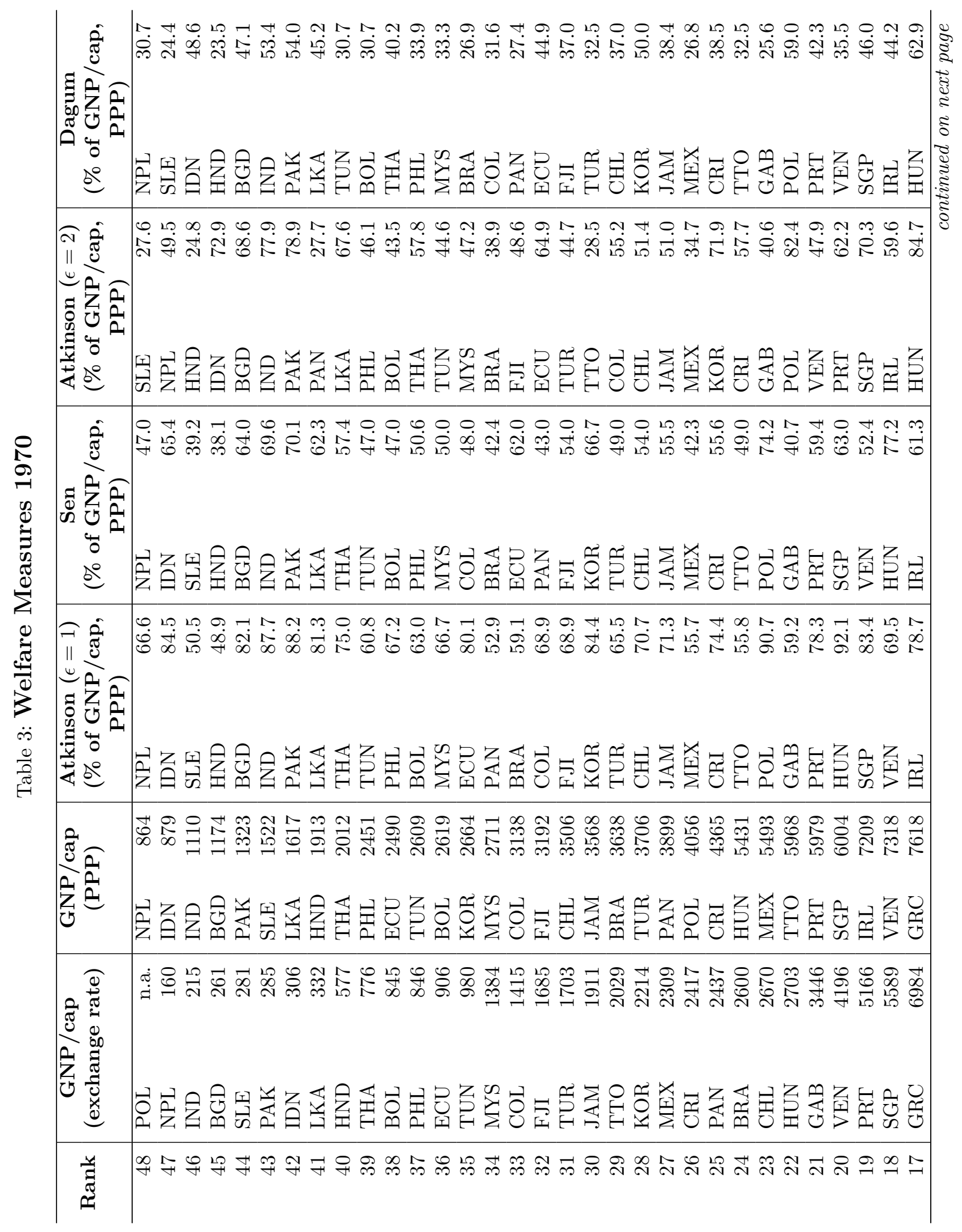




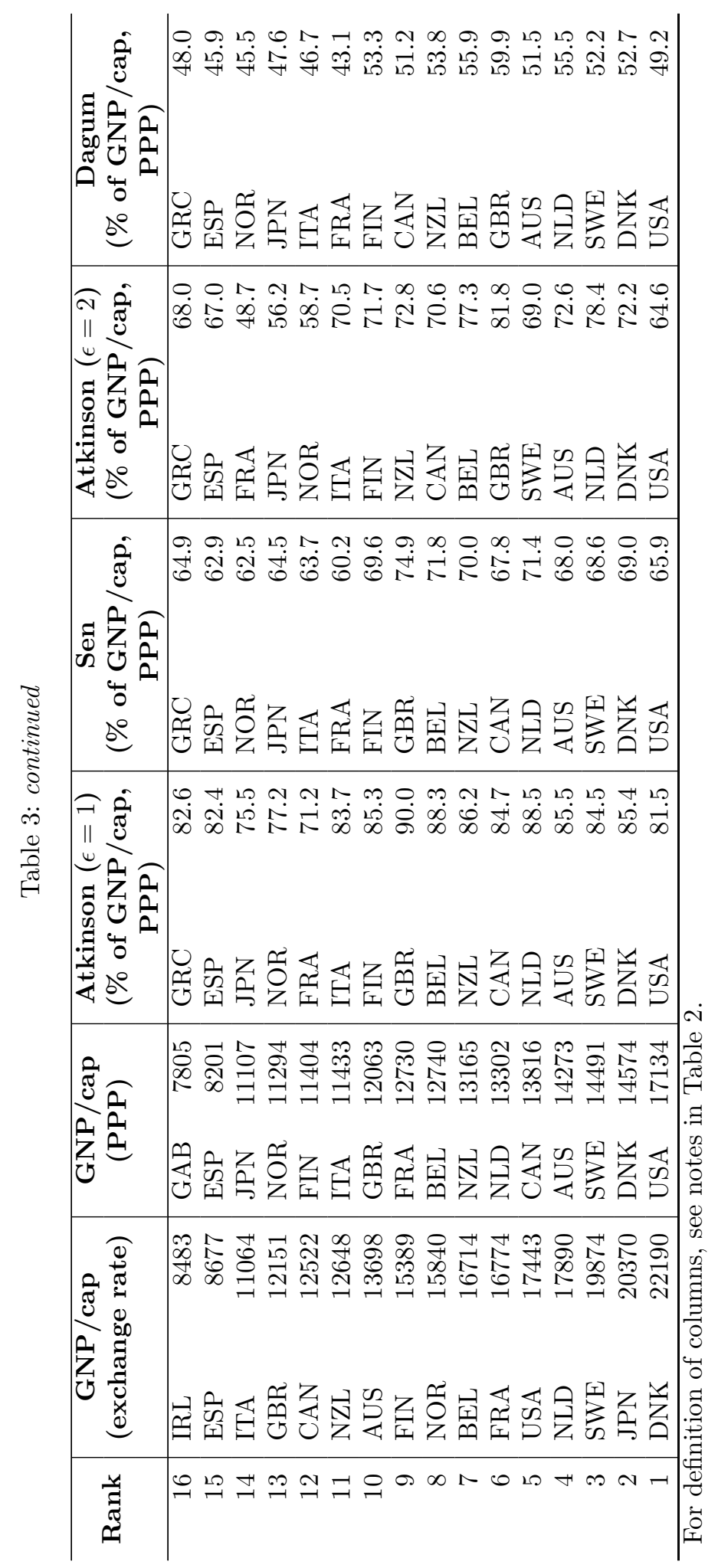




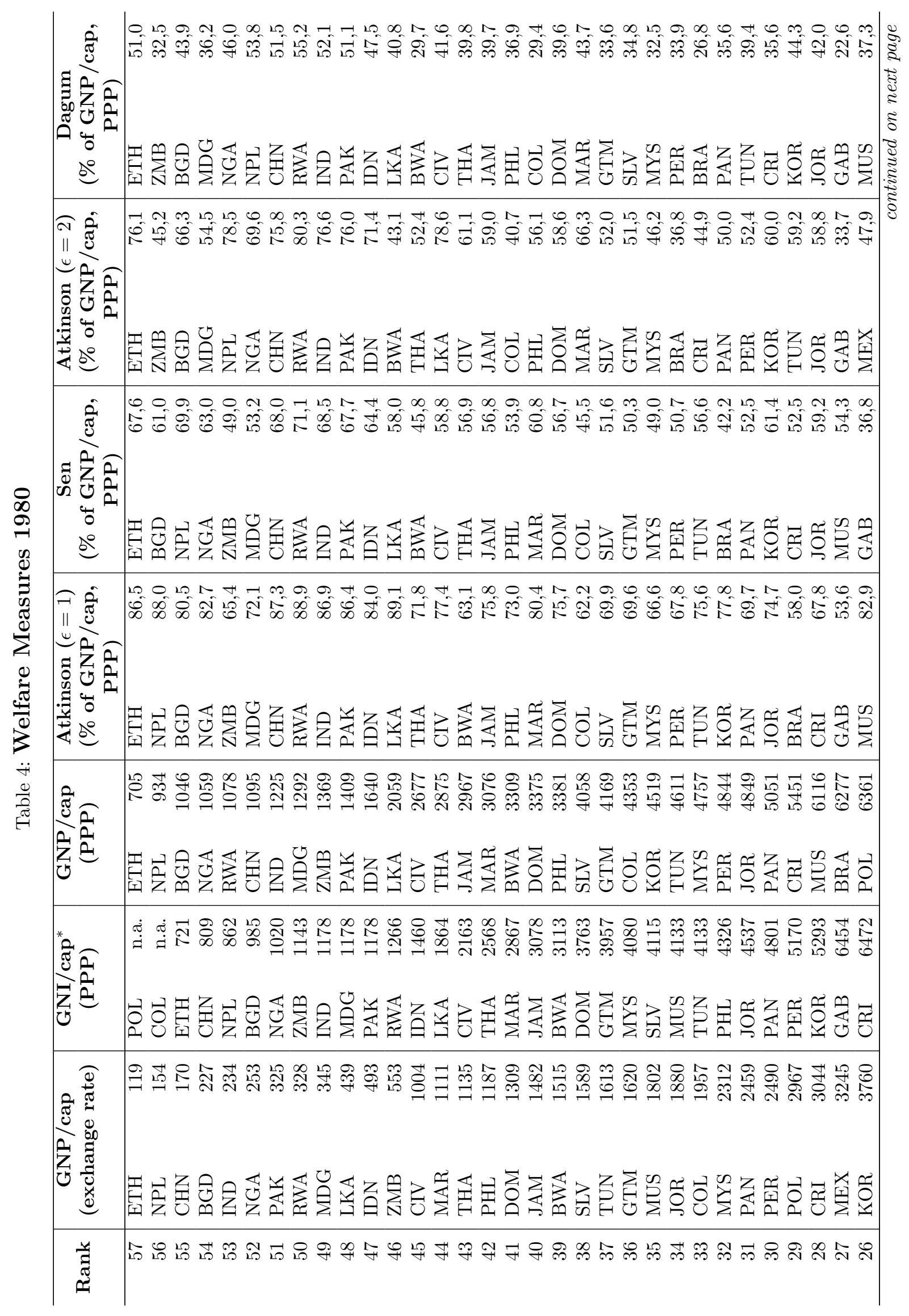




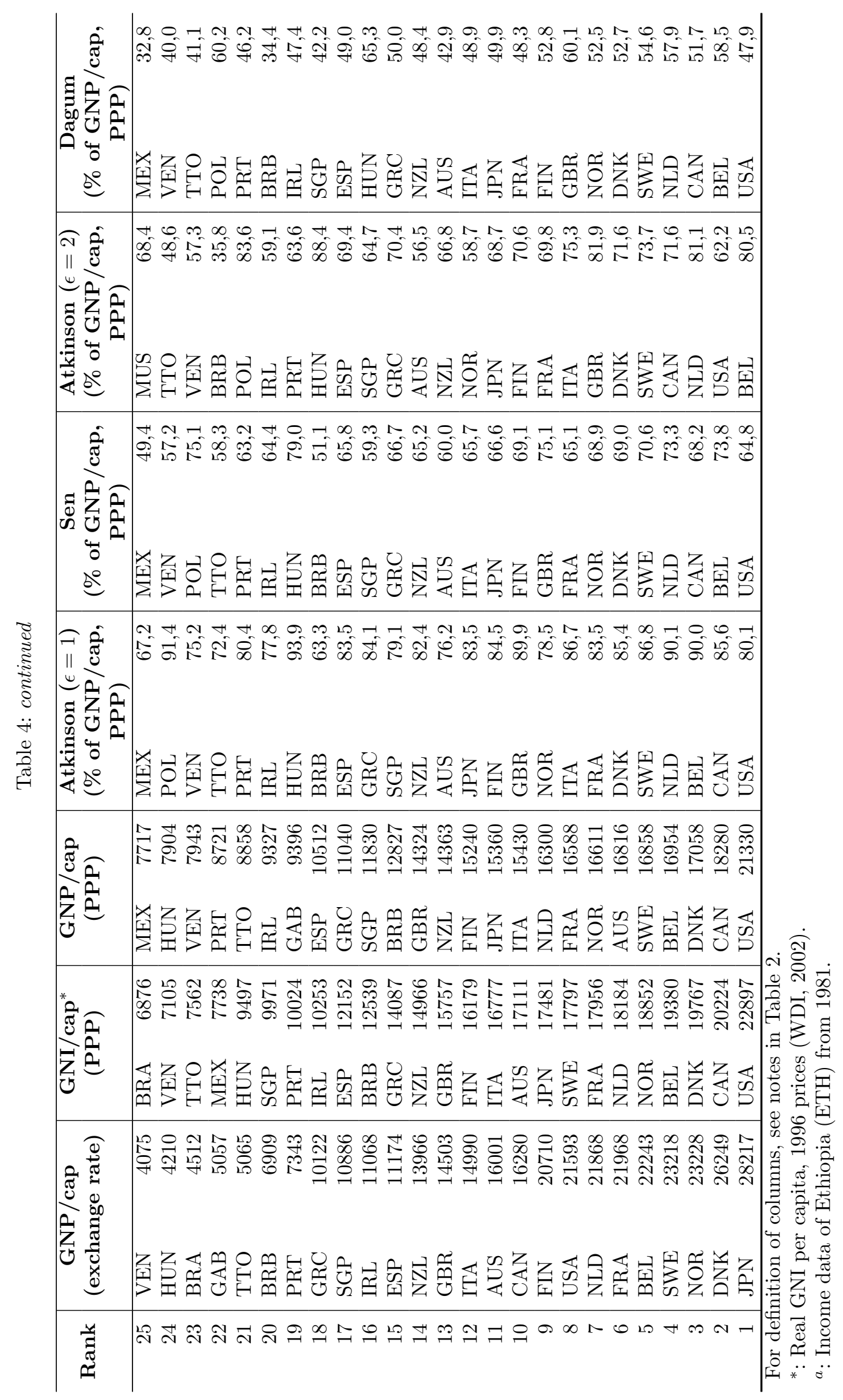




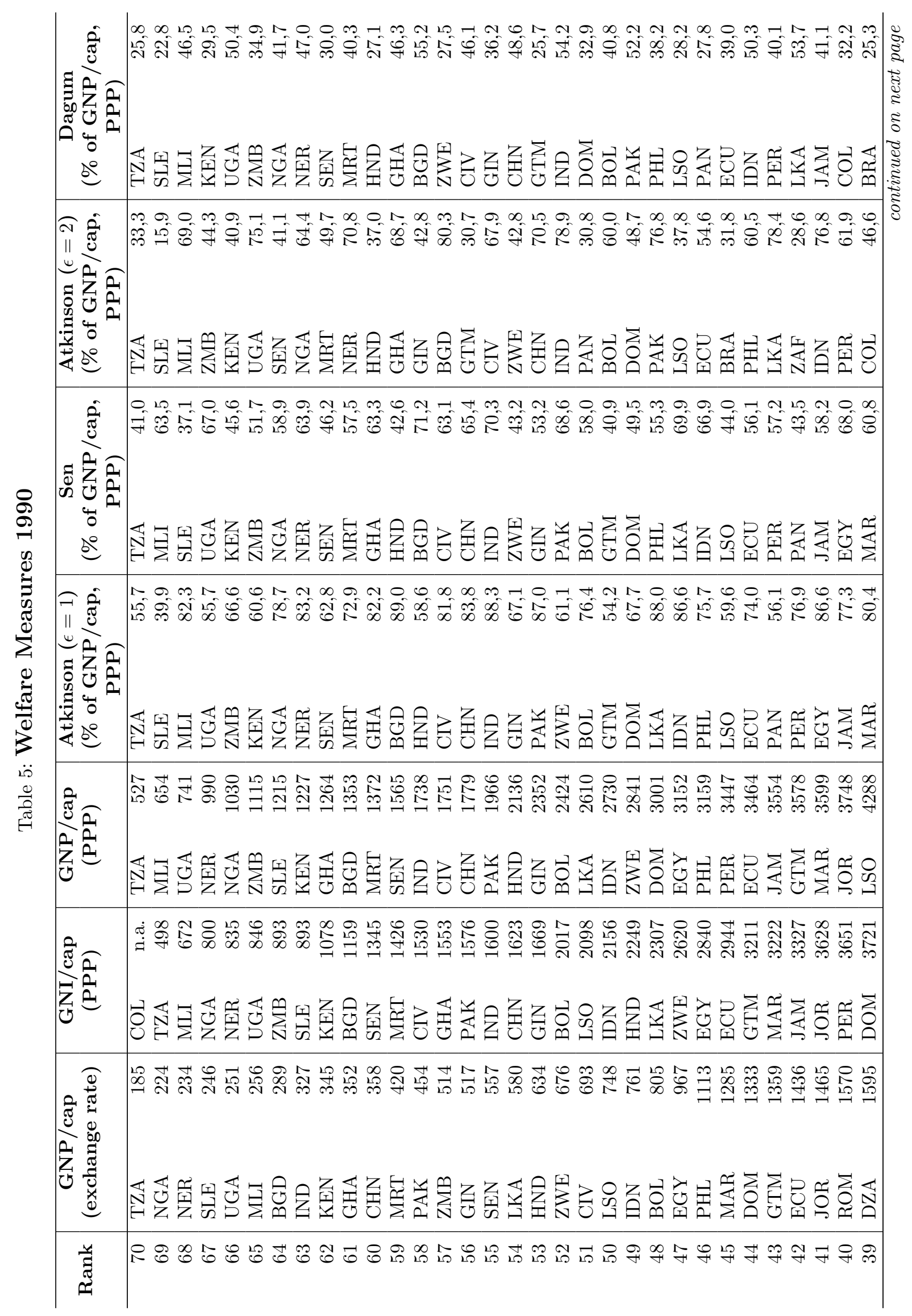




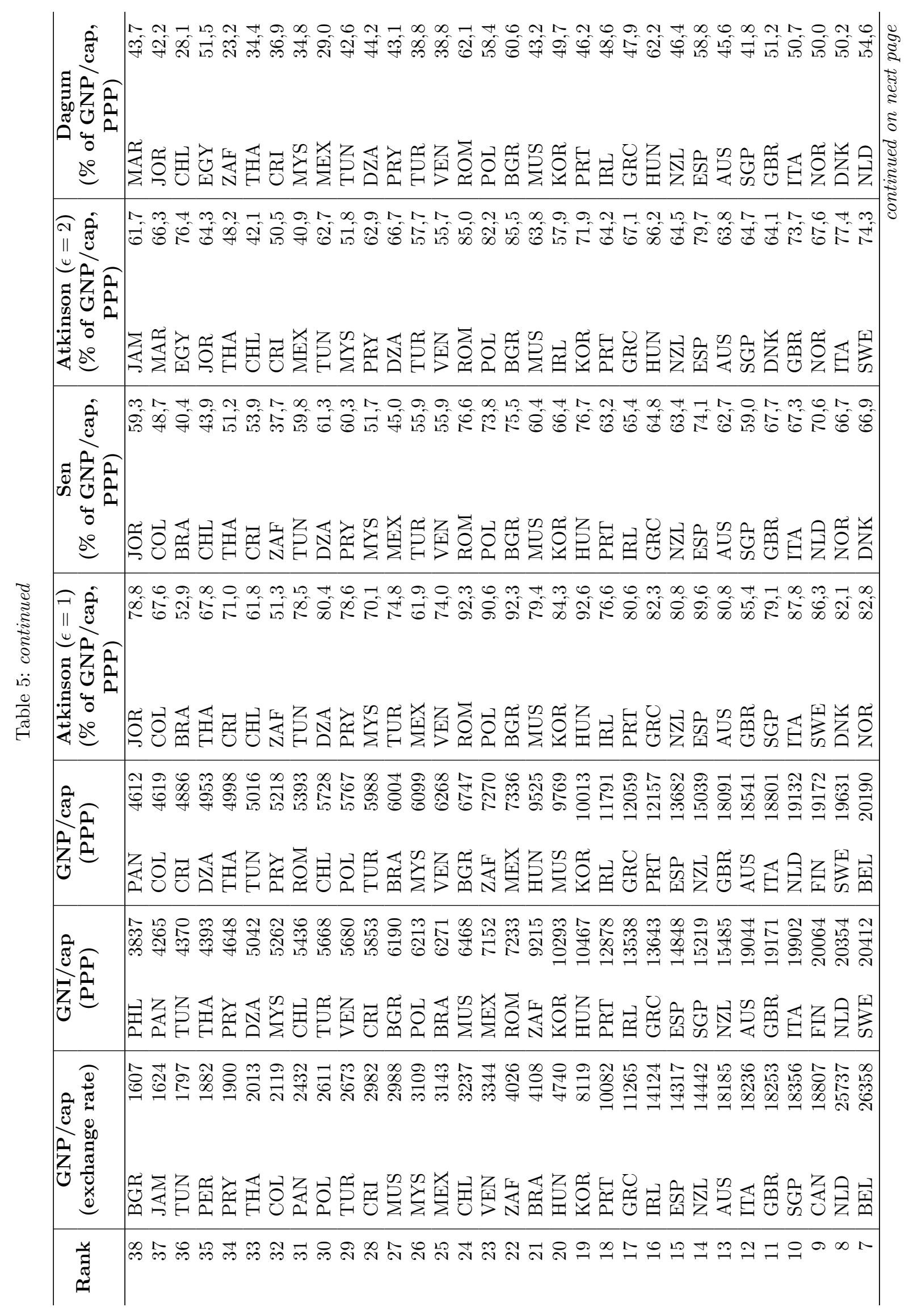




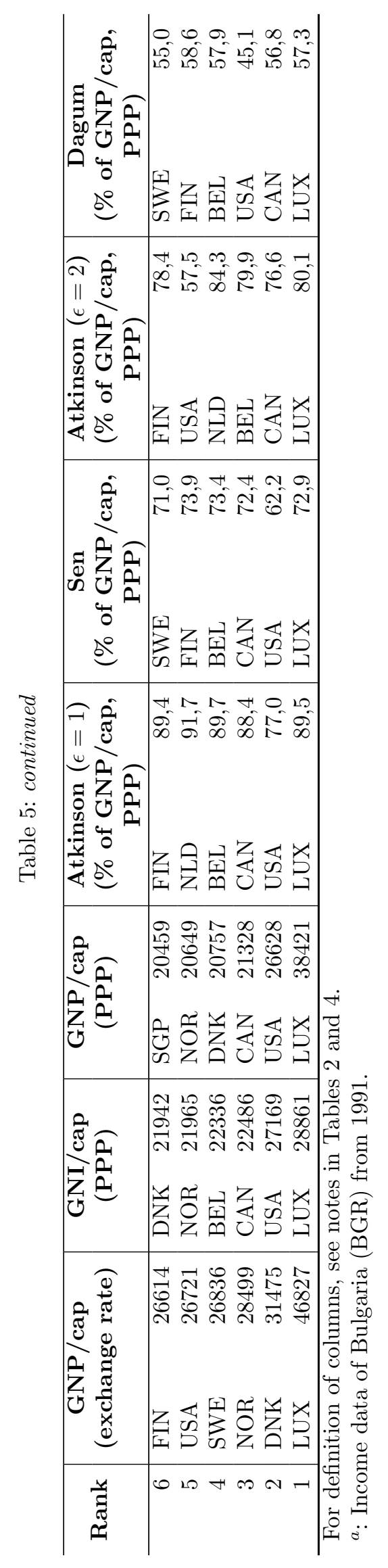




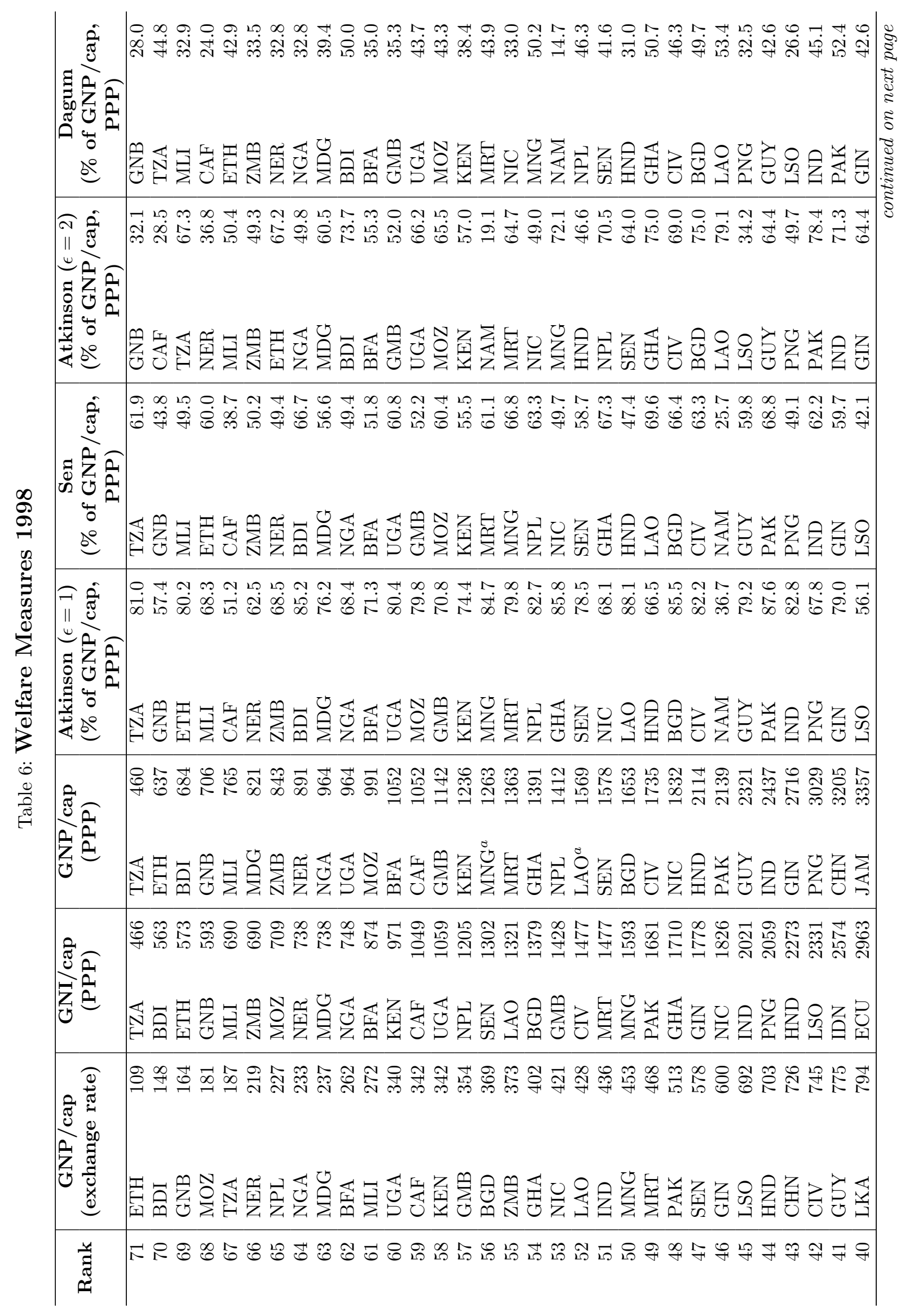




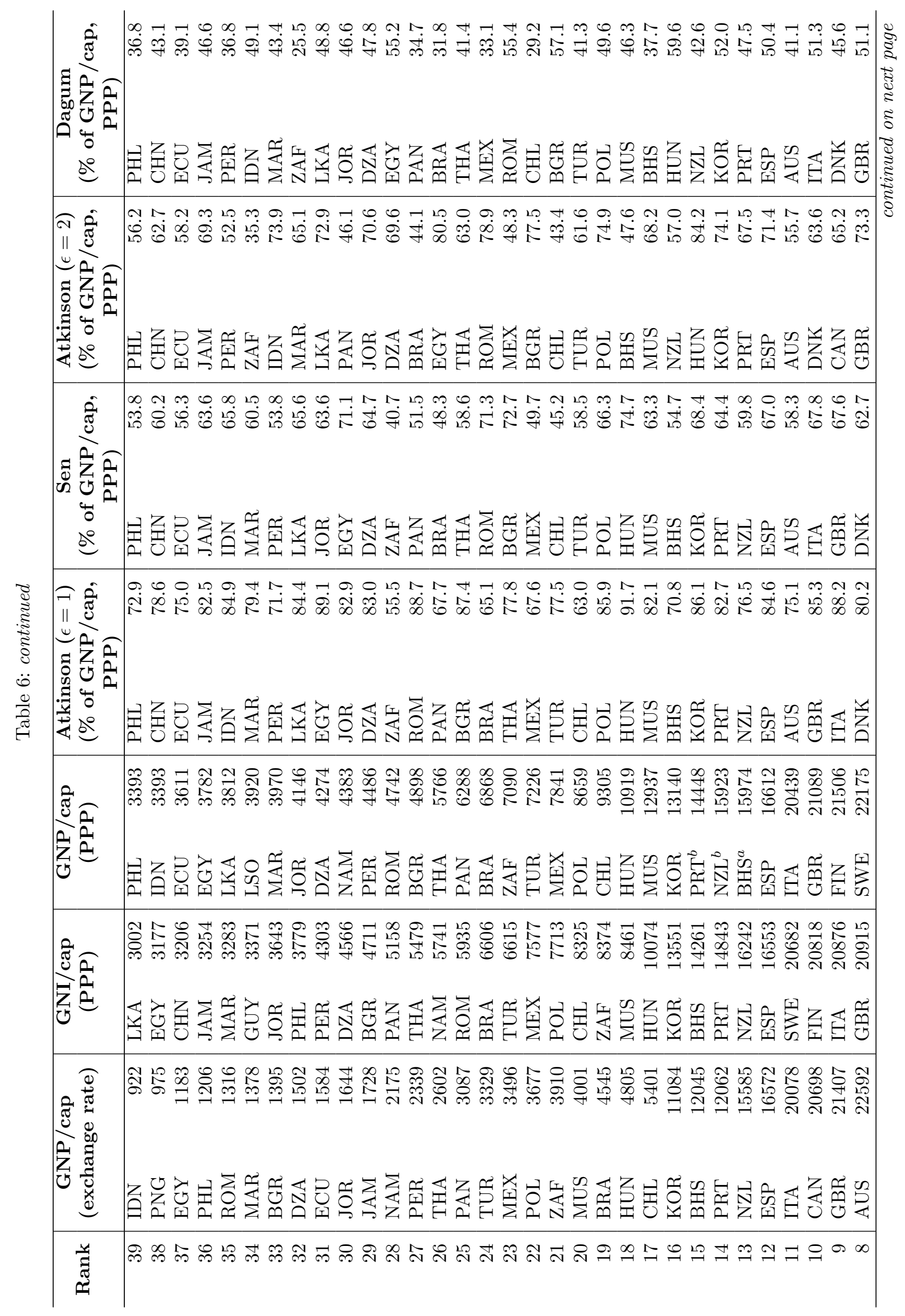




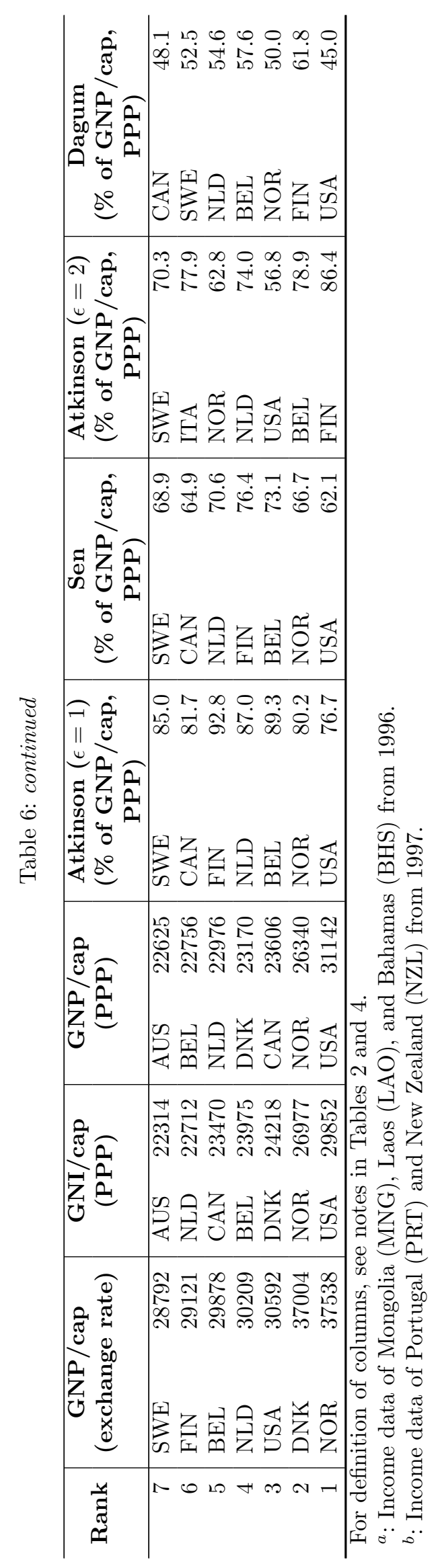




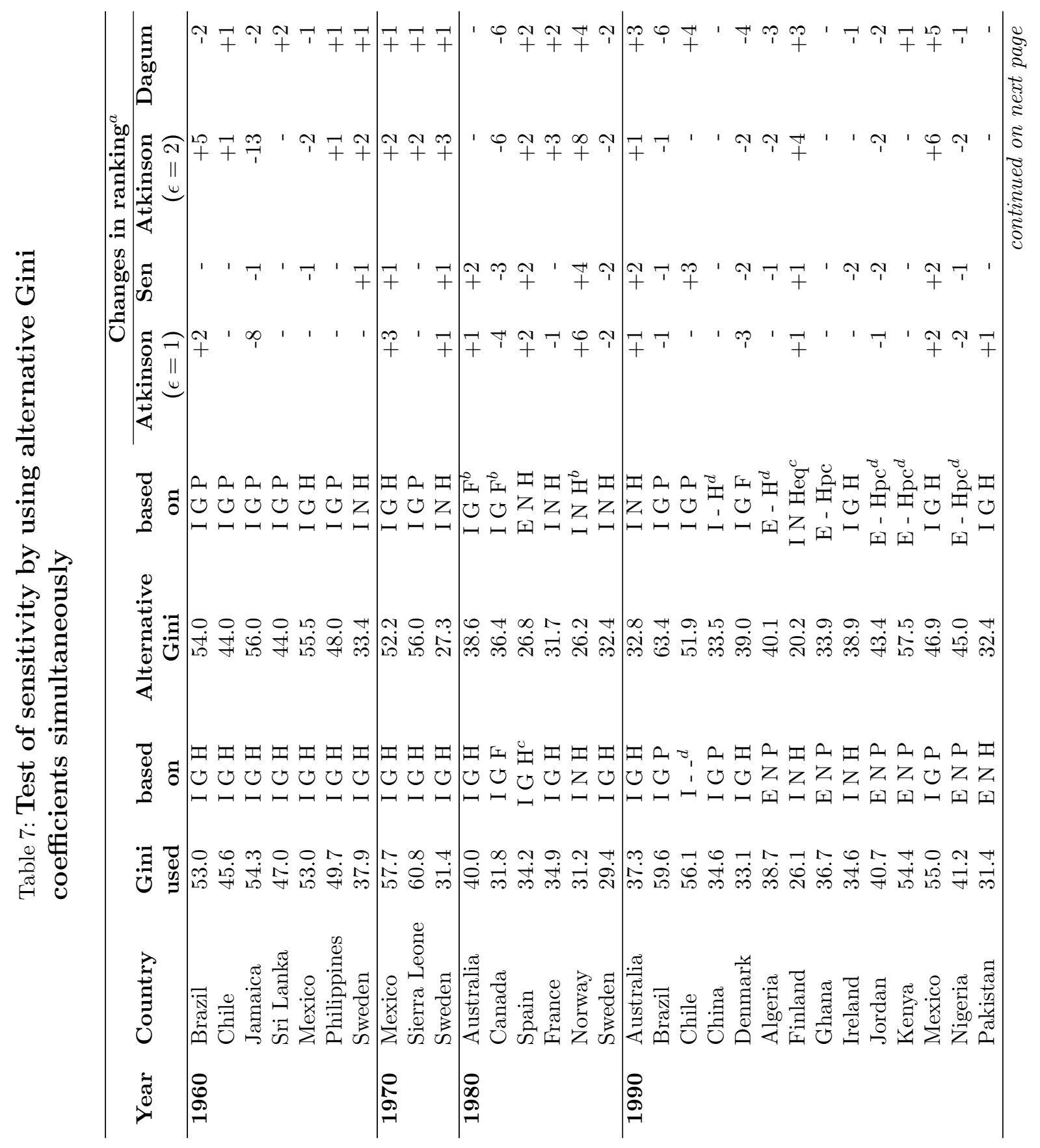




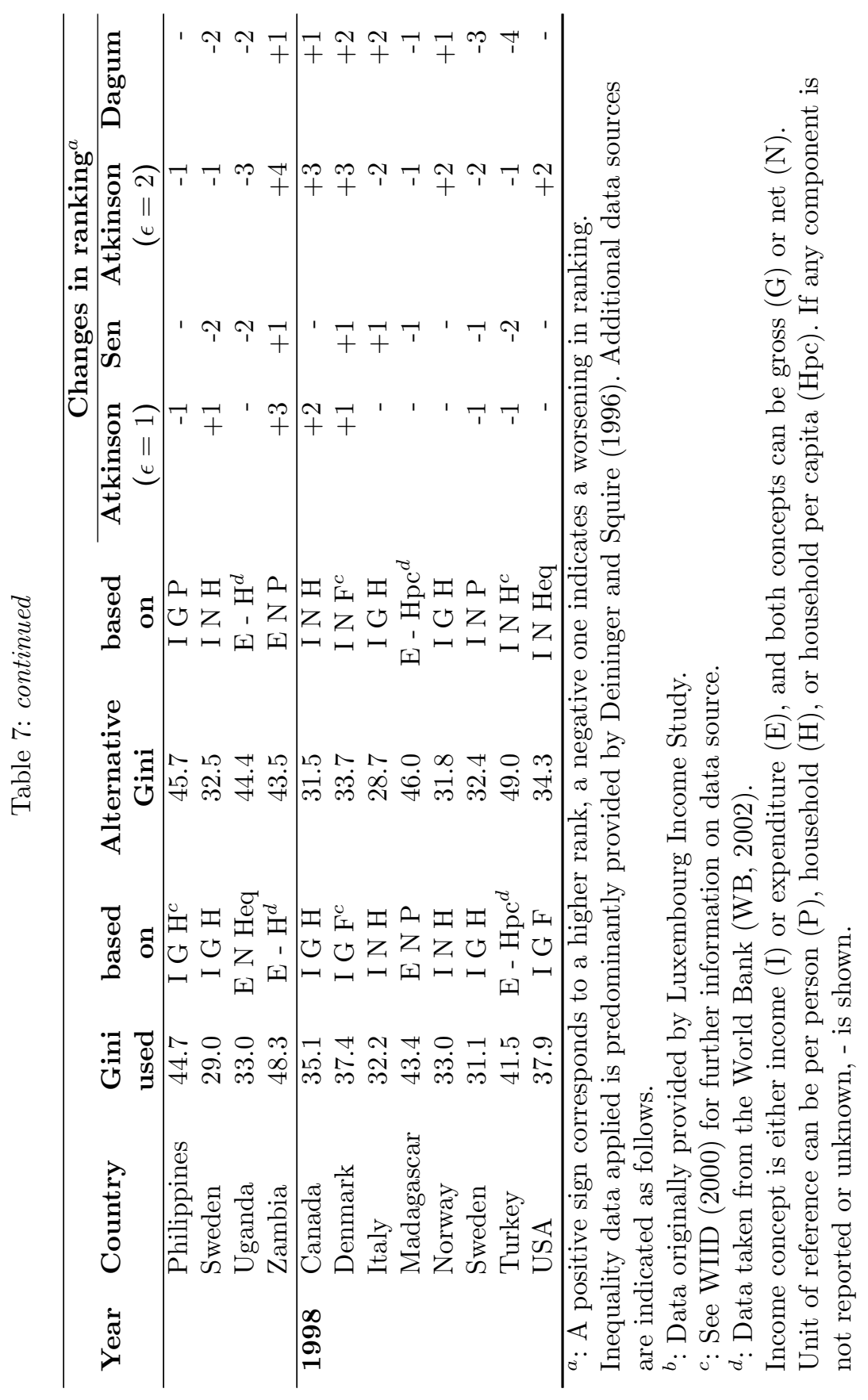


Table 8: Determinants of Gini coefficients

\begin{tabular}{|c|c|c|c|c|}
\hline & \multicolumn{2}{|c|}{ (1) } & \multicolumn{2}{|c|}{$(2)$} \\
\hline Expenditure & $-3.89^{* *}$ & $(0.38)$ & $-3.59^{* *}$ & $(0.38)$ \\
\hline Net income & $-1.94^{* *}$ & $(0.27)$ & $1.38^{* *}$ & $(0.47)$ \\
\hline Unknown income & 1.66 & $(1.43)$ & 1.81 & $(1.40)$ \\
\hline Household & $0.99^{* *}$ & $(0.28)$ & $1.09^{* *}$ & $(0.27)$ \\
\hline Family & 0.73 & $(0.45)$ & 0.85 & $(0.44)$ \\
\hline Unknown reference unit & -1.51 & $(1.55)$ & -1.45 & $(1.52)$ \\
\hline Equivalized & $-4.72^{* *}$ & $(0.30)$ & $-4.46^{* *}$ & $(0.29)$ \\
\hline Primary source unknown & $1.81^{* *}$ & $(0.63)$ & $1.93^{* *}$ & $(0.61)$ \\
\hline No consistent source & -0.31 & $(0.25)$ & -0.34 & $(0.24)$ \\
\hline OECD $*$ Net income & & & $-4.74^{* *}$ & $(0.55)$ \\
\hline Intercept & $36.03^{* *}$ & $(0.26)$ & $35.84^{* *}$ & $(0.26)$ \\
\hline $\mathrm{N}$ & & & 20 & \\
\hline $\mathrm{R}^{2}$ & & & 0 . & \\
\hline
\end{tabular}

Table 9: Change in rankings due to adjusted Gini coefficients

\begin{tabular}{lrrrrr}
\hline \hline & No change & 1 Rank & 2 Ranks & 3 Ranks & 4+ Ranks \\
\hline Sen measure & & & & & \\
1960 & 35 & 7 & 0 & 0 & 1 \\
1970 & 28 & 18 & 2 & 0 & 0 \\
1980 & 26 & 22 & 6 & 2 & 1 \\
1990 & 42 & 22 & 3 & 3 & 0 \\
1998 & 37 & 24 & 7 & 2 & 1 \\
Dagum measure & & & & & \\
1960 & 24 & 12 & 7 & 0 & 0 \\
1970 & 29 & 14 & 1 & 4 & 0 \\
1980 & 26 & 21 & 7 & 3 & 0 \\
1990 & 31 & 21 & 15 & 3 & 0 \\
1998 & 29 & 33 & 6 & 1 & 2 \\
\hline \hline
\end{tabular}

Table 10: Average Gini coefficients over time

\begin{tabular}{cccc}
\hline \hline Year & Average Gini & $\begin{array}{c}\text { Average } \\
\text { adjusted Gini }\end{array}$ & $\begin{array}{c}\text { Number of } \\
\text { observations }\end{array}$ \\
\hline $1960 \mathrm{~s}$ & 37.9 & 38.6 & 197 \\
$1970 \mathrm{~s}$ & 34.8 & 36.2 & 427 \\
$1980 \mathrm{~s}$ & 32.7 & 34.7 & 780 \\
$1990 \mathrm{~s}$ & 34.3 & 36.6 & 666 \\
\hline \hline
\end{tabular}

Adjusted Gini coefficients are based on regression 1 reported in Table 8. 
Table 11: Temporal trends in inequality and Kuznets curve

\begin{tabular}{|c|c|c|c|c|c|c|c|c|}
\hline & \multicolumn{2}{|c|}{ (1) } & \multicolumn{2}{|c|}{$(2)$} & \multicolumn{2}{|c|}{$(3)$} & \multicolumn{2}{|c|}{$(4)$} \\
\hline Intercept & $34.55^{* *}$ & $(0.19)$ & $39.77^{* *}$ & $(0.89)$ & $37.22^{* *}$ & $(0.82)$ & $40.63^{* *}$ & $(1.06)$ \\
\hline Dummy $1960 \mathrm{~s}$ & $1.31^{* *}$ & $(0.40)$ & $1.36^{* *}$ & $(0.40)$ & & & & \\
\hline Dummy 1970s & -0.45 & $(0.32)$ & -0.44 & $(0.32)$ & & & & \\
\hline Dummy 1980s & $-1.23^{* *}$ & $(0.26)$ & $-1.24^{* *}$ & $(0.26)$ & & & & \\
\hline Income per capita & & & & & $-0.20^{* *}$ & $(0.06)$ & $-0.75^{* *}$ & $(0.16)$ \\
\hline Income per capita, inverse & & & & & 1.03 & $(1.61)$ & & \\
\hline Income per capita, squared & & & & & & & $0.02^{* *}$ & $(0.00)$ \\
\hline $\mathrm{N}$ & 20 & & 20 & & & & 15 & \\
\hline $\mathrm{R}^{2}$ & 0. & & $0 .($ & & & & $0 .($ & \\
\hline
\end{tabular}

Significance levels: $*: 5 \% \quad * *: 1 \% ; \quad$ Standard errors in parentheses.

Specification (1) estimates fixed effects, specification (2) random effects. Reference category is the period 1990-1998. Specifications (3) and (4) test for the Kuznets hypothesis using a fixed effects estimation.

Table 12: Income mobility, 1970-1998

\begin{tabular}{cc|ccccc}
\hline \hline & & \multicolumn{5}{|c}{$\mathbf{1 9 9 8}$} \\
& & 1st & 2nd & 3rd & 4th & 5th \\
\hline \multirow{4}{*}{$\mathbf{1 9 7 0}$} & 1st & 35 & 7 & 0 & 0 & 0 \\
& 2nd & 25 & 10 & 4 & 2 & 0 \\
& 3rd & 16 & 13 & 13 & 6 & 0 \\
& 4th & 4 & 14 & 28 & 47 & 28 \\
& 5th & 0 & 0 & 0 & 10 & 98 \\
\hline \hline
\end{tabular}

Rows and columns show the number of country quintiles falling into the first to fifth world quintile in 1970 and 1998, respectively. 
Figure 1: Welfare comparison: Brazil versus Indonesia, 1980-1998

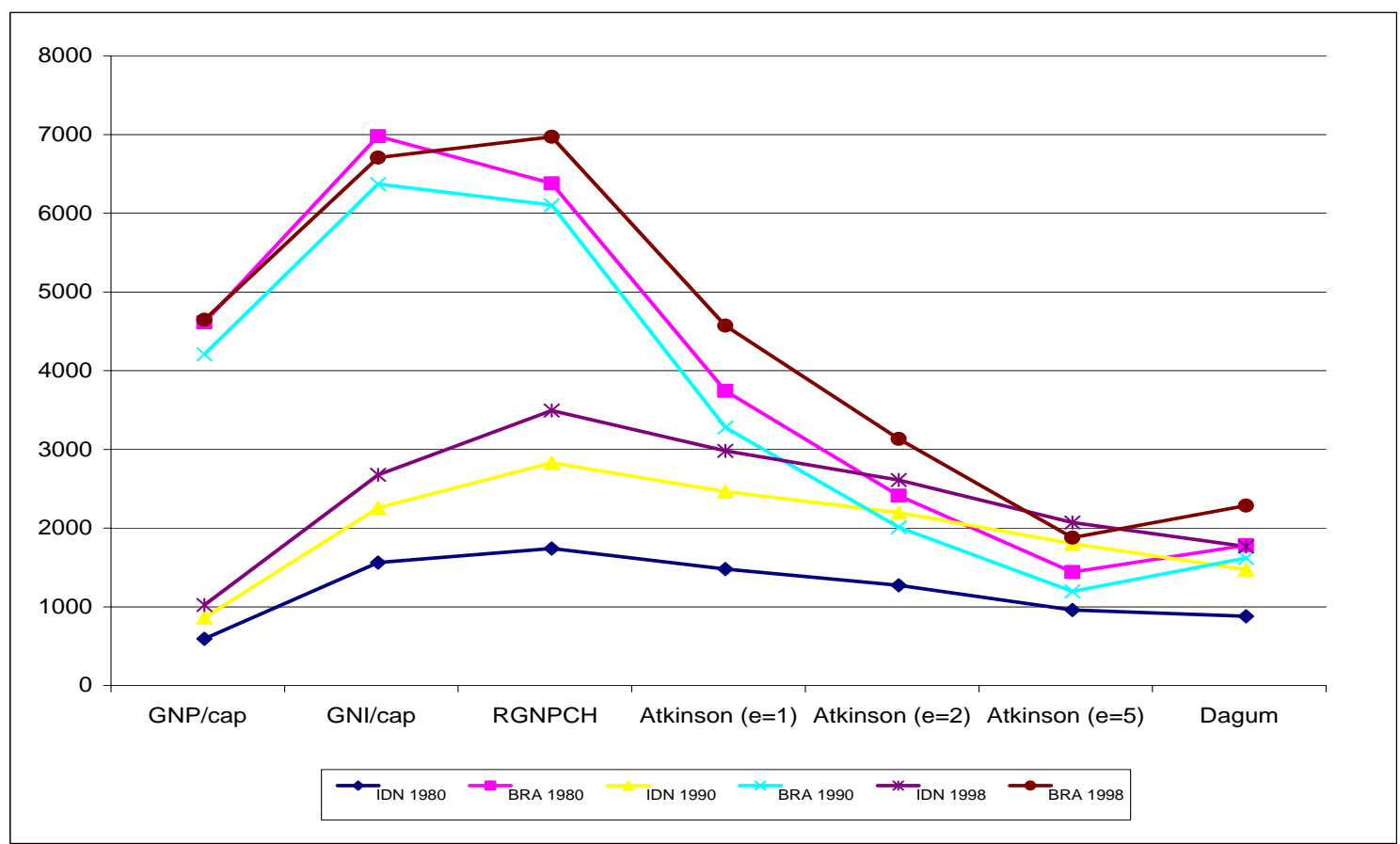

Notes: GNP/cap: GNP per capita, constant 1996 US-Dollars (WDI, 1999, 2001). GNI/cap: Real GNI per capita, 1996 prices (WDI, 2002). RGNPCH: Real GNP per capita, 1996 prices (Summers and Heston, 1991; Heston, Summers, and Aten, 2001).

Figure 2: Welfare comparison: Canada versus USA, 1970-1990

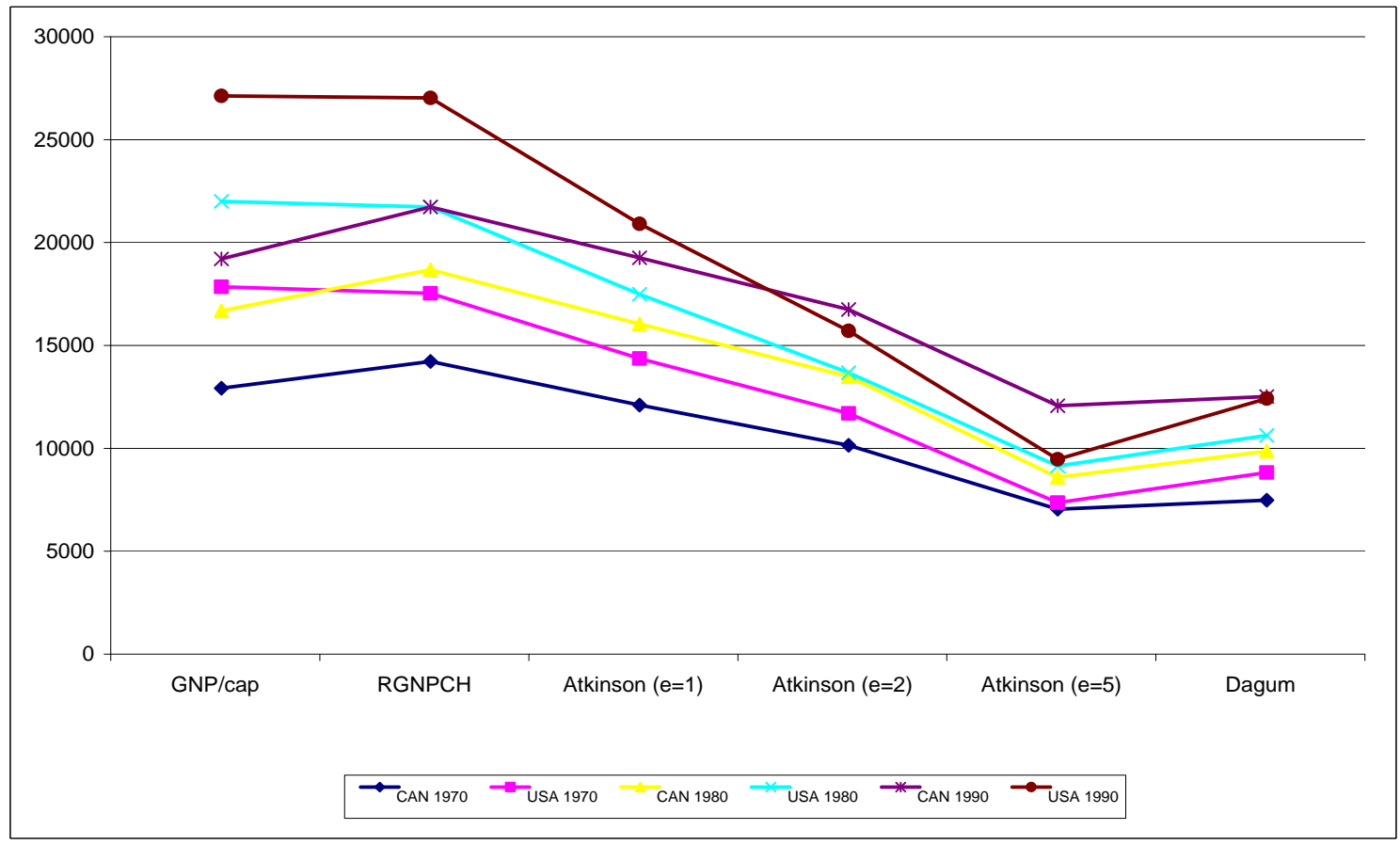

Notes: For definition of incomes see notes in Figure 1. 
Figure 3: Welfare comparison: Sri Lanka versus Peru, 1980-1998

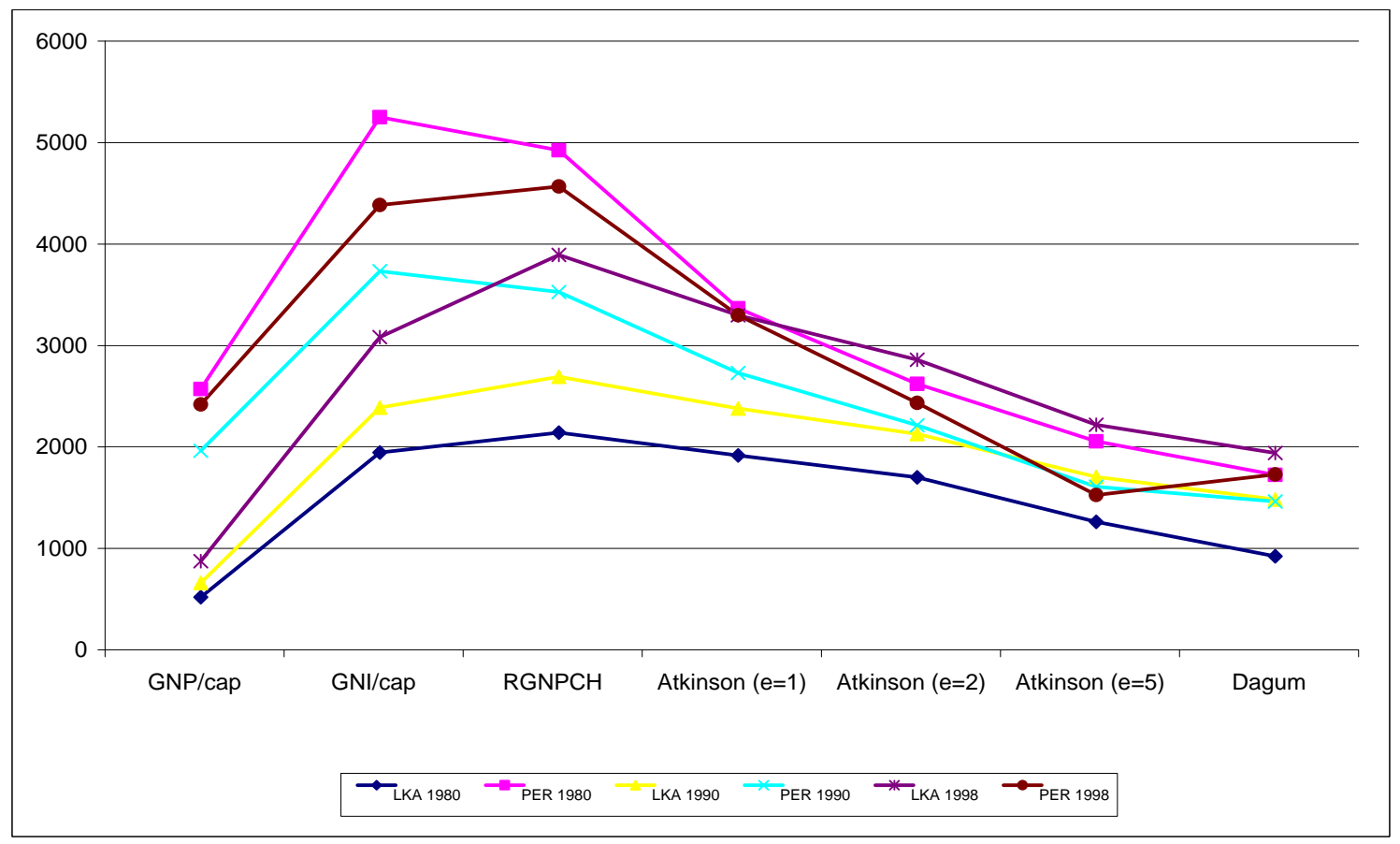

Notes: For definition of incomes see notes in Figure 1.

Figure 4: Average annual growth of well-being in Brazil

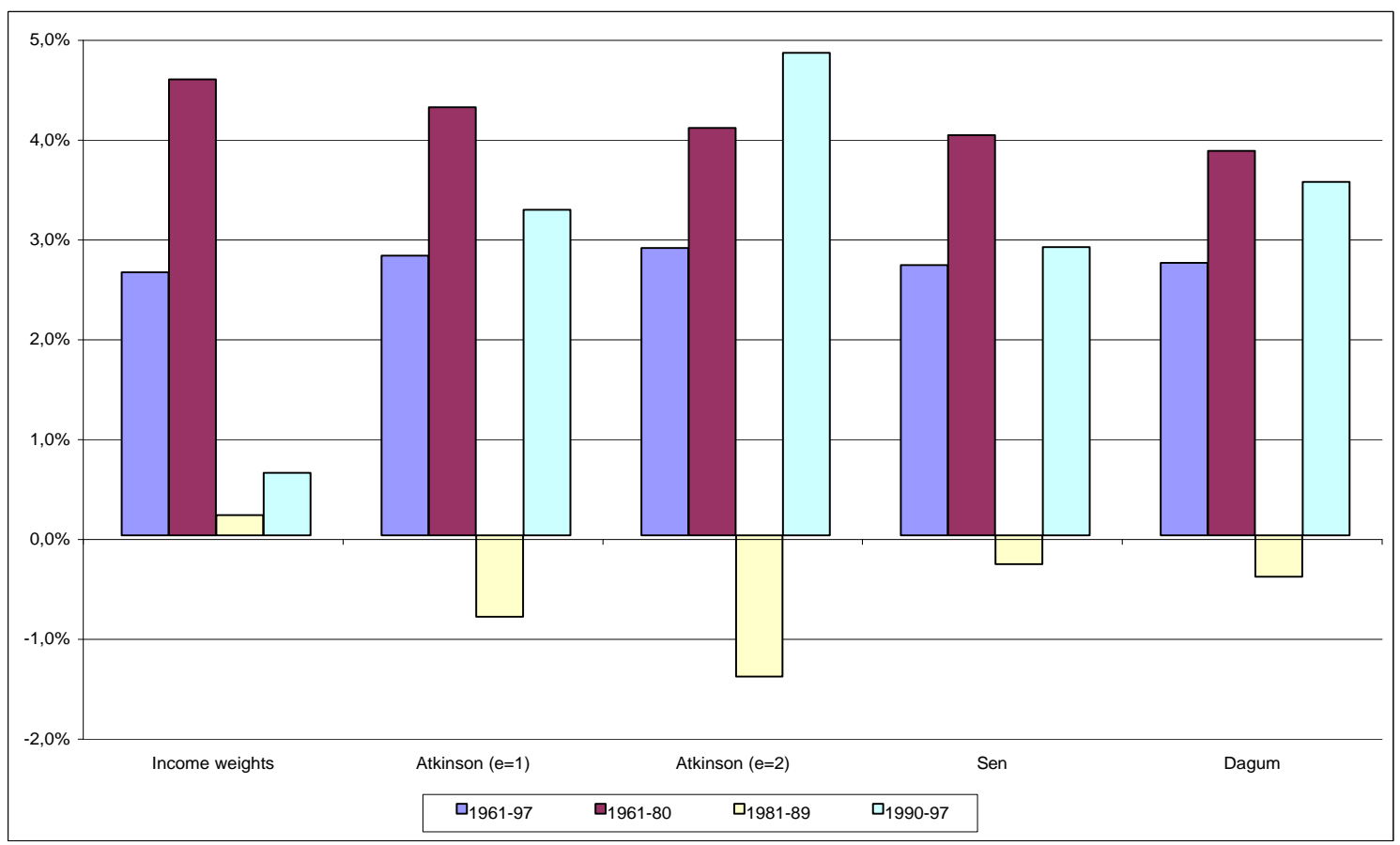

Notes: The income concept used here is GDP per capita at market prices in constant local currency (WDI, 2002). 
Figure 5: Average annual growth of well-being in Indonesia

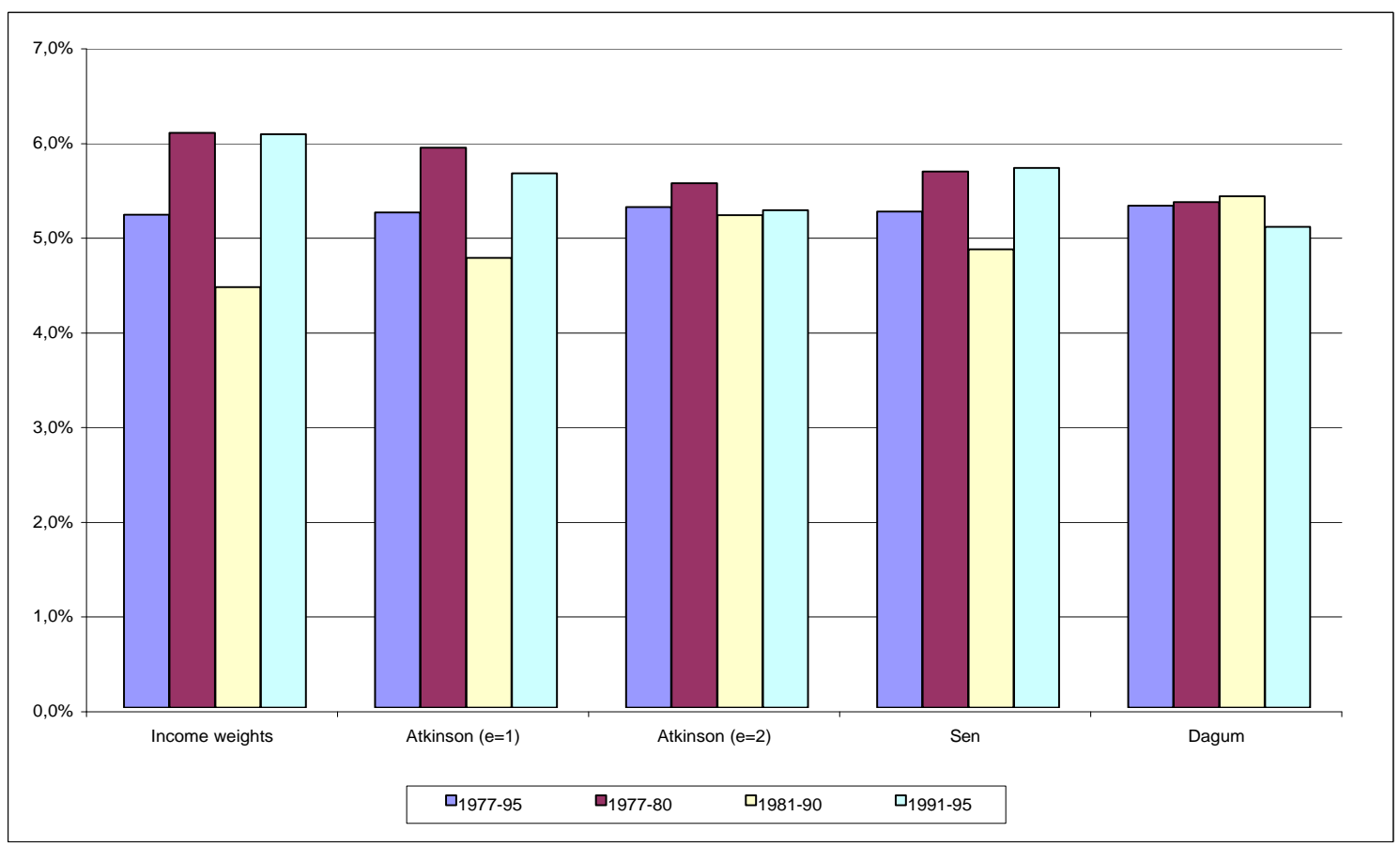

Notes: See notes in Figure 4.

Figure 6: Average annual growth of well-being in Canada

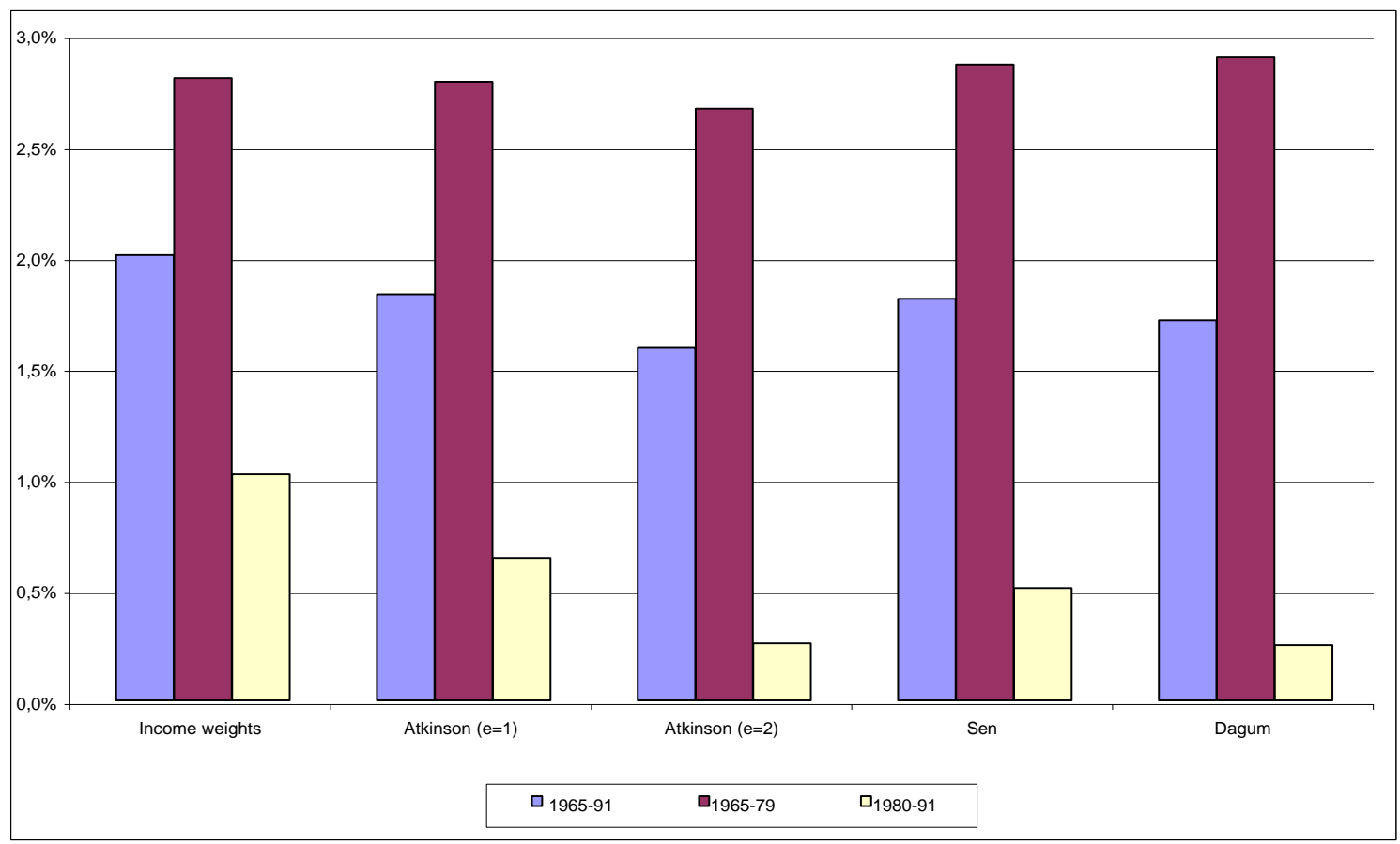

Notes: See notes in Figure 4. 
Figure 7: Average annual growth of well-being in Finland

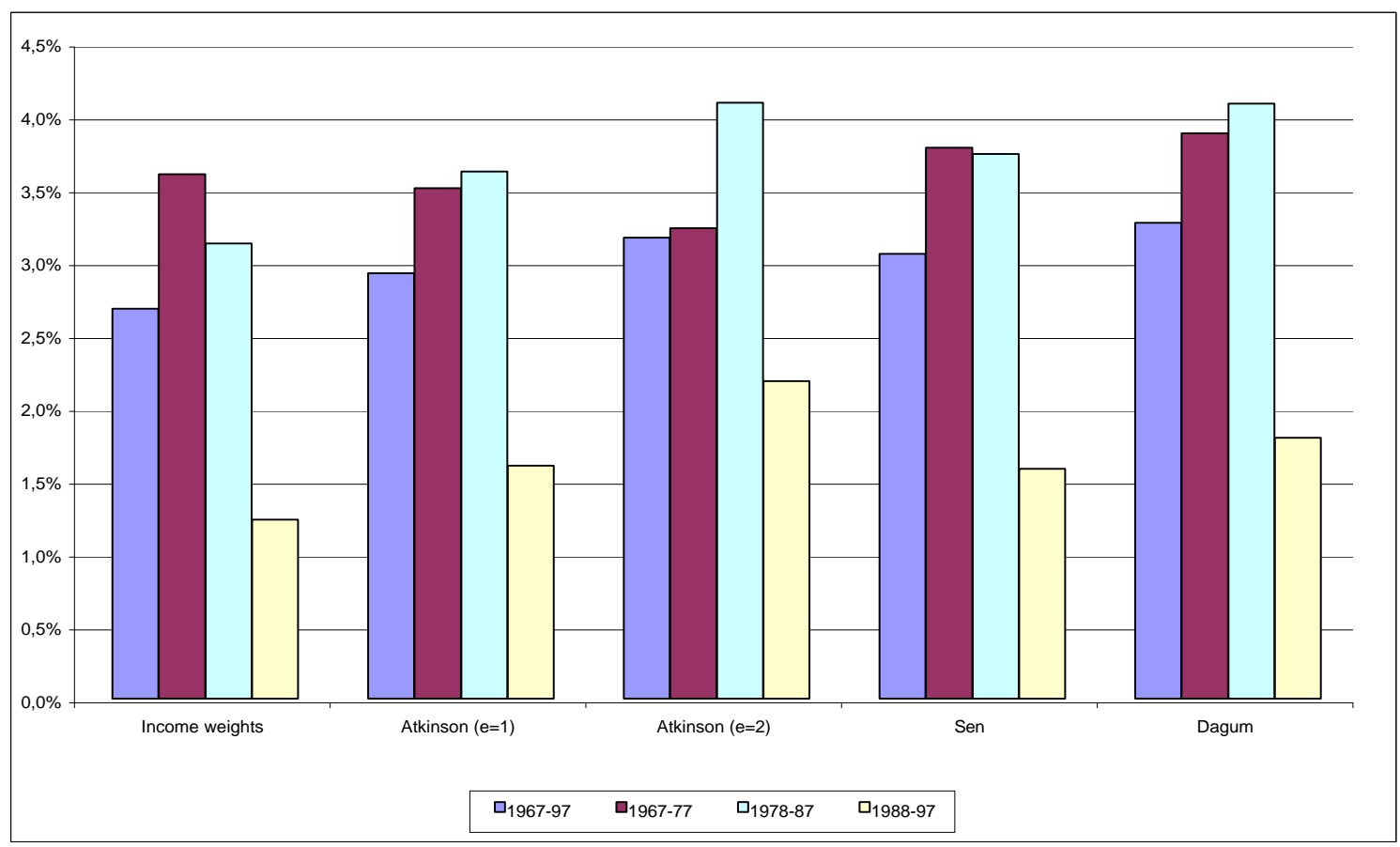

Notes: See notes in Figure 4.

Figure 8: Average annual growth of well-being in China

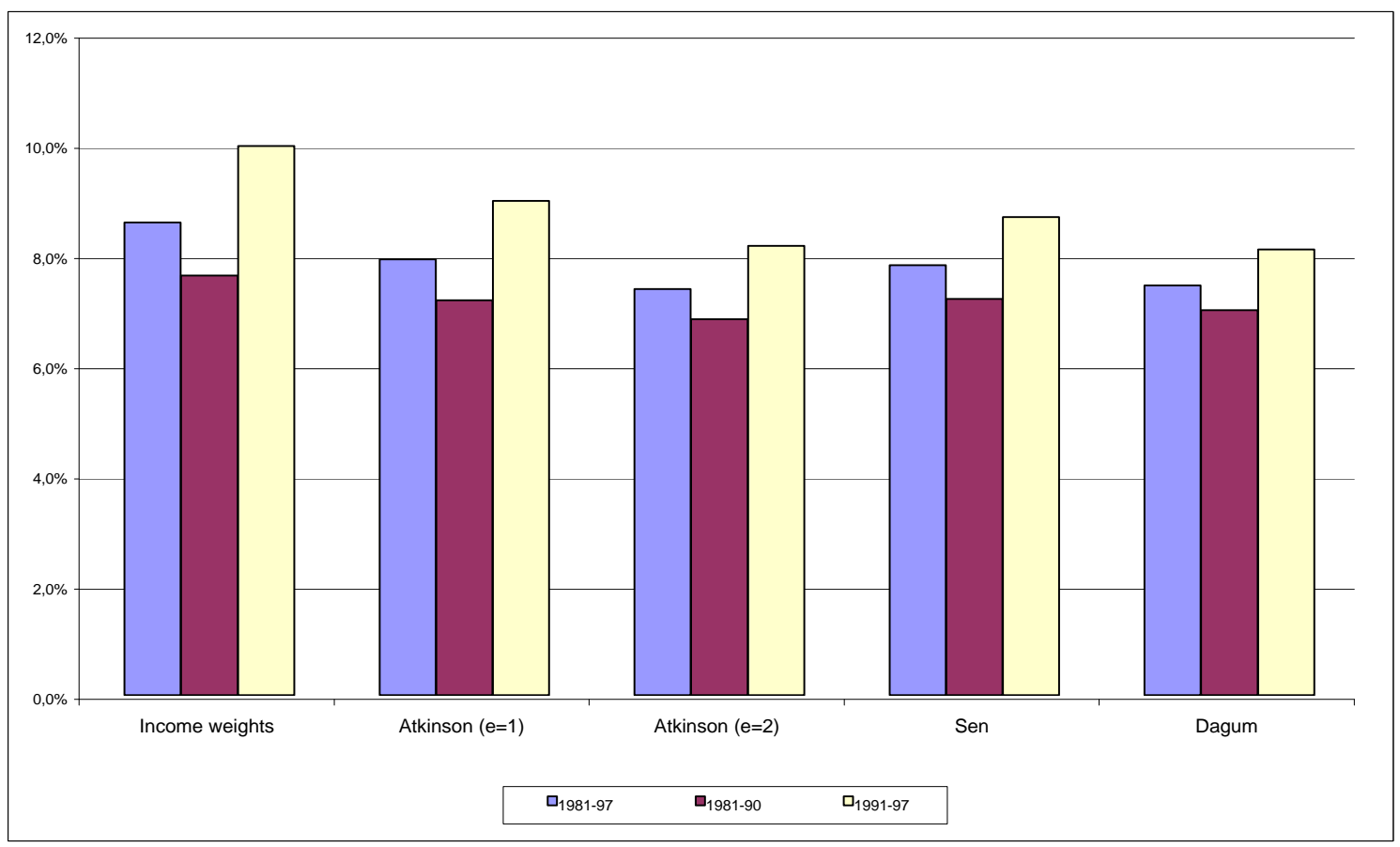

Notes: See notes in Figure 4. 
Figure 9: Average annual growth of well-being in the US

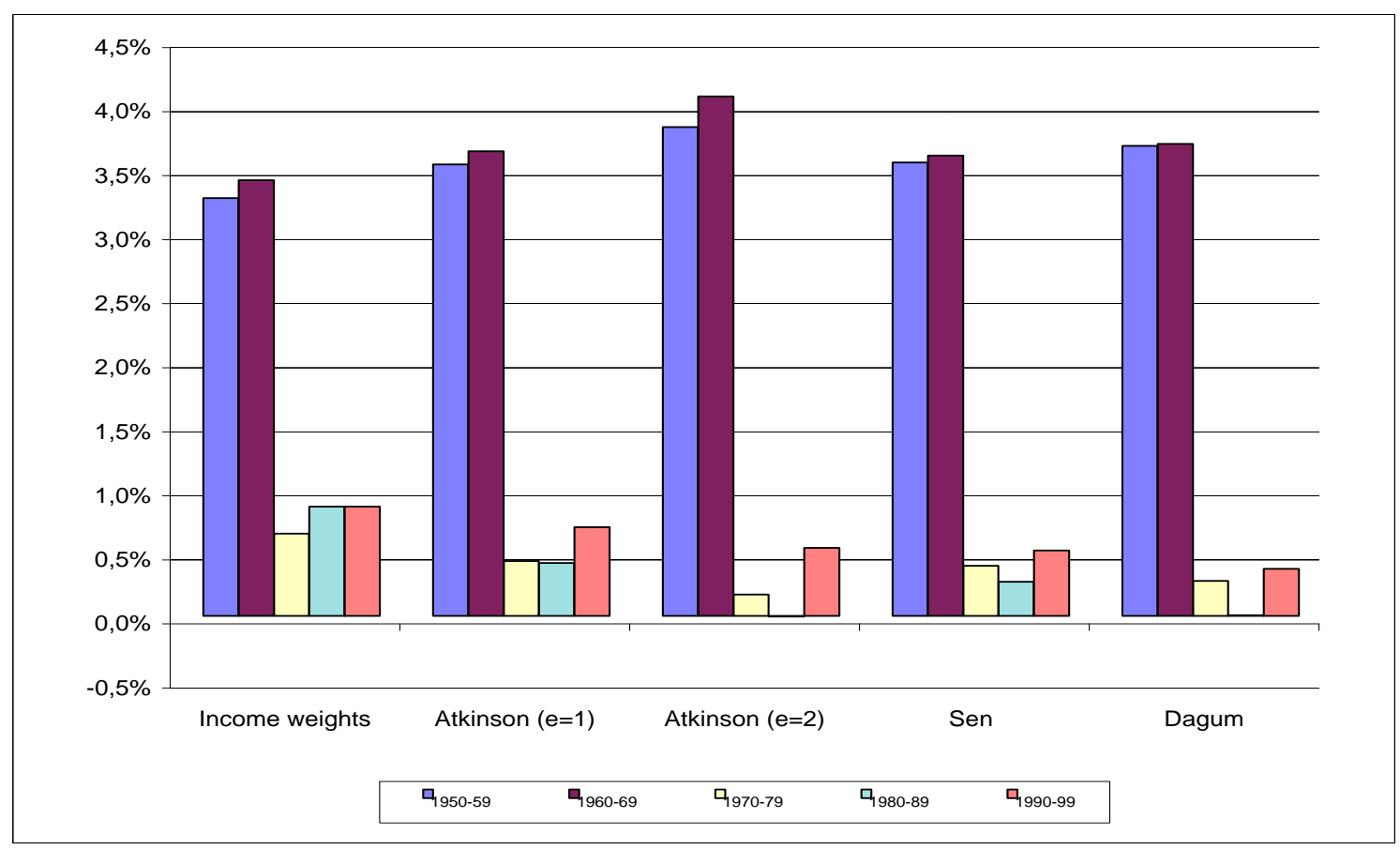

Notes: Calculations are based on U.S. census data.

Figure 10: 'Great society versus new economy'

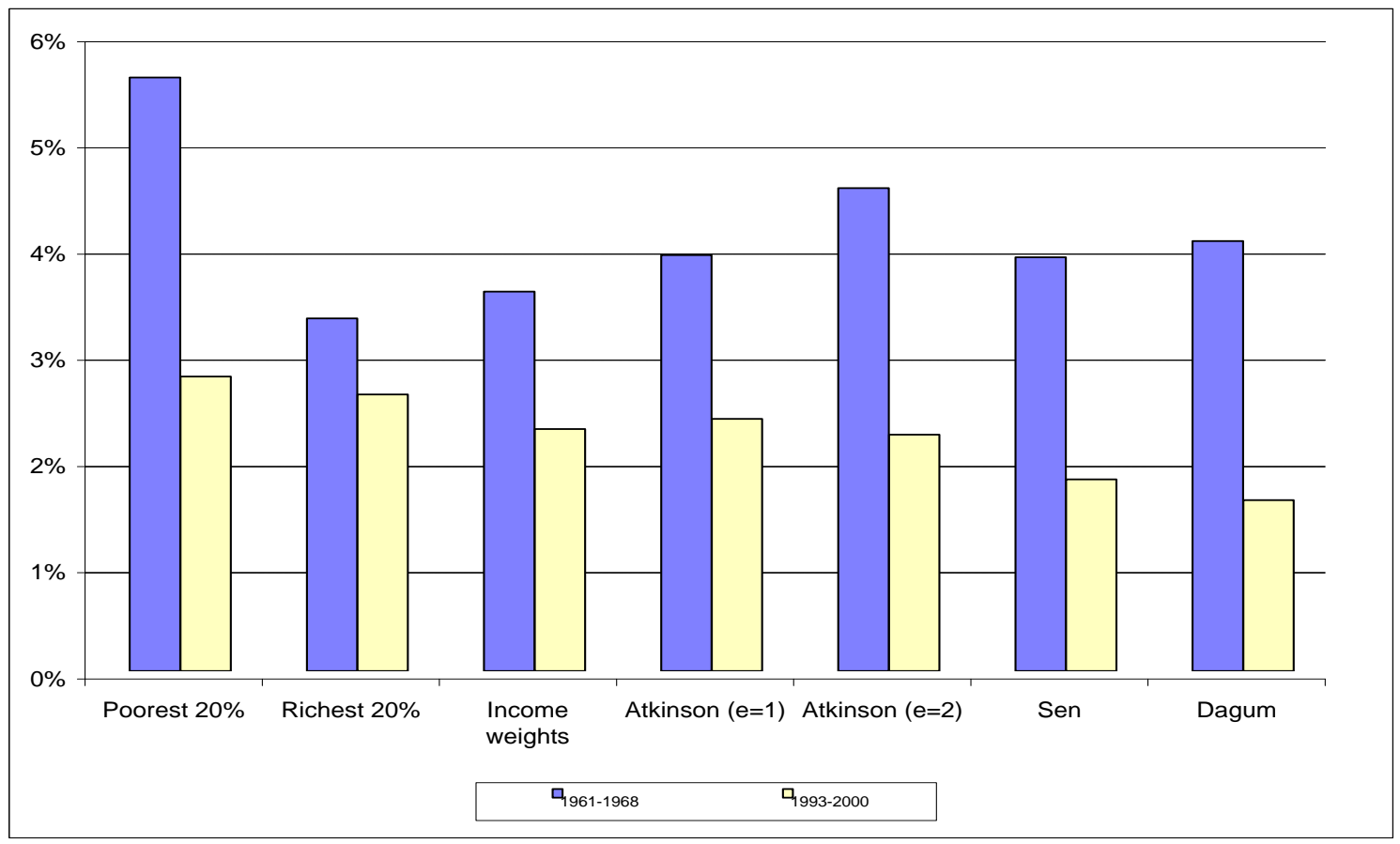

Notes: See notes in Figure 9. 
Figure 11: Average annual growth of well-being in Great Britain

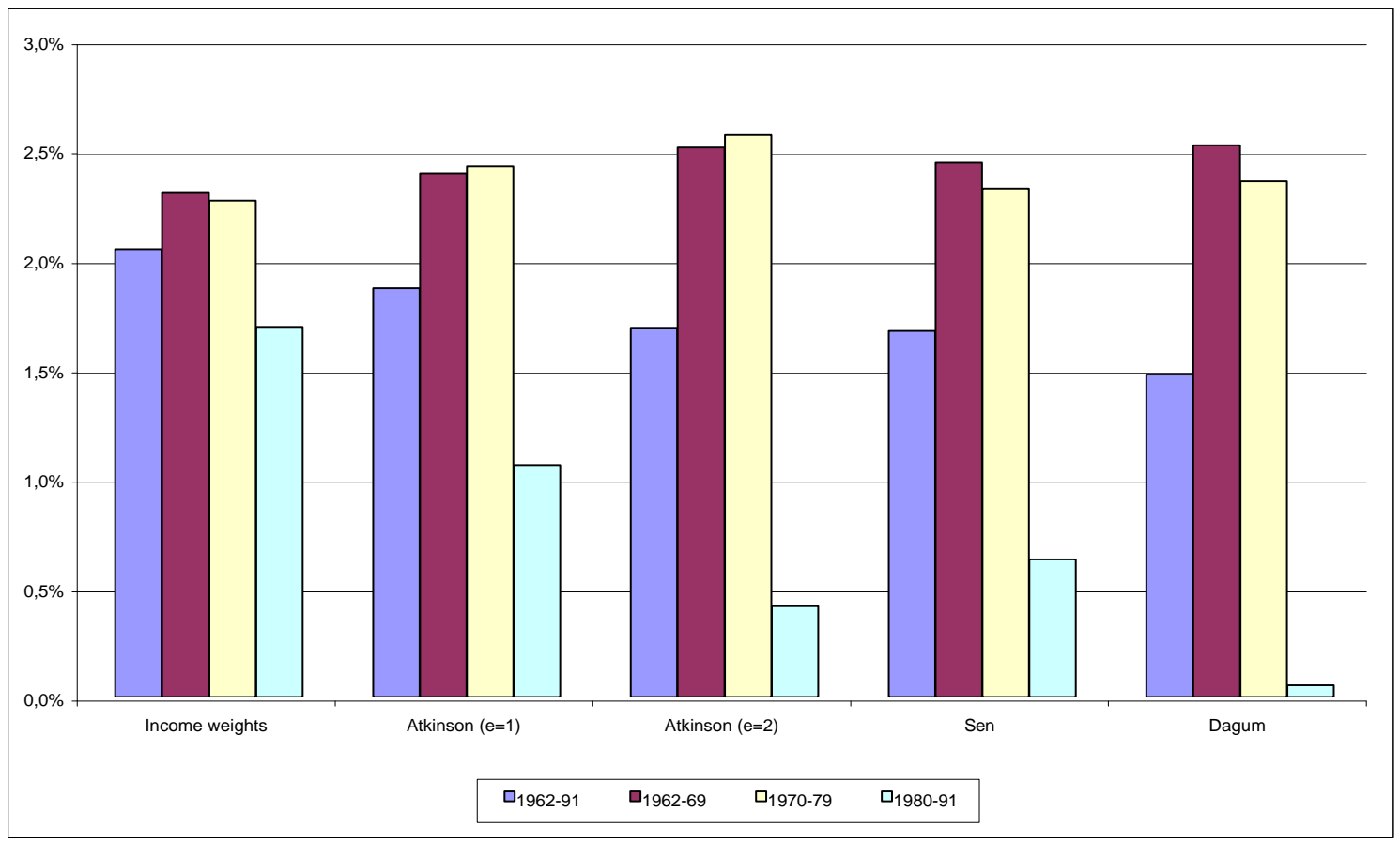

Notes: See notes in Figure 4.

Figure 12: World well-being (excluding socialist countries), 1970-1998

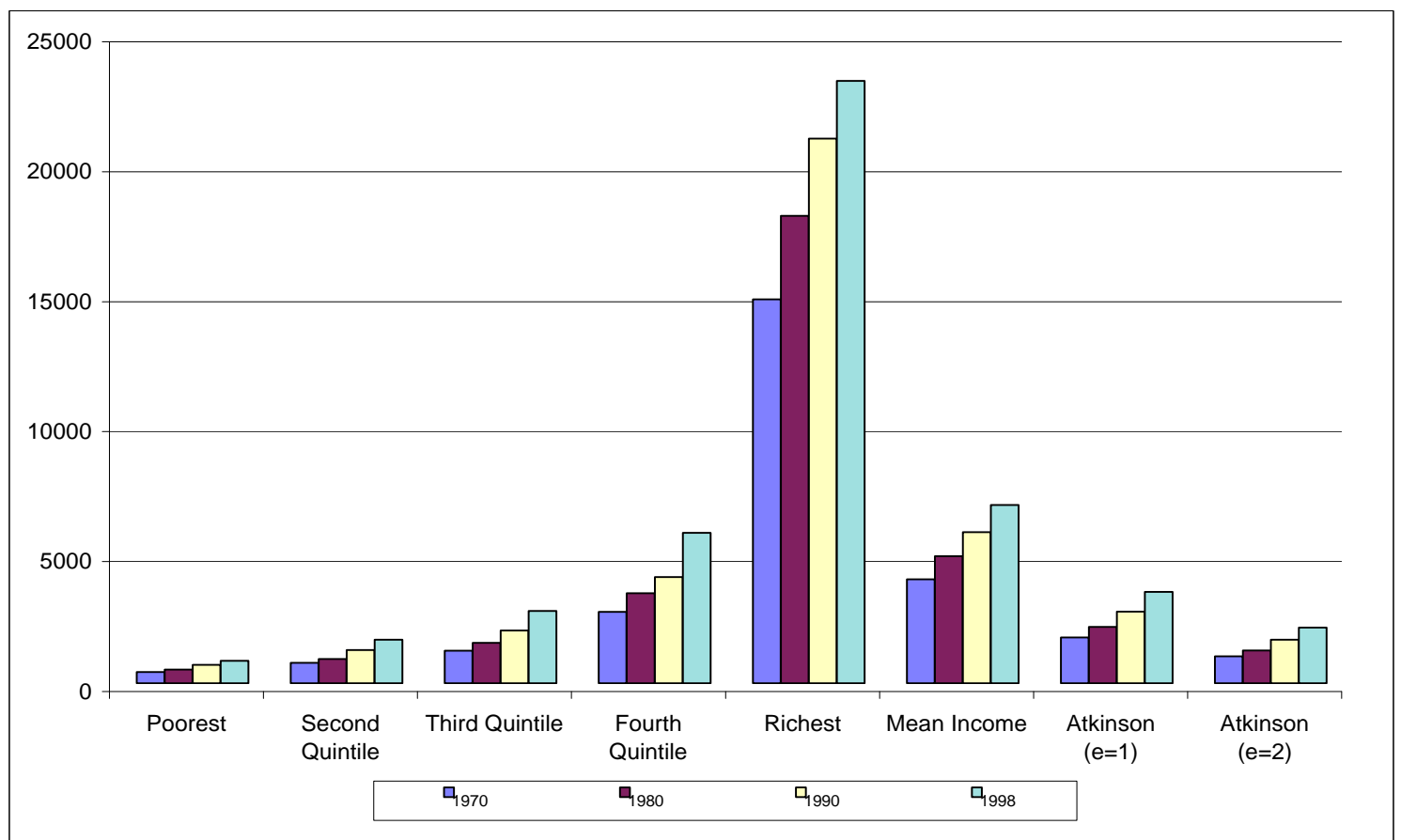


Figure 13: Growth in world well-being (excluding socialist countries), 1970-1998

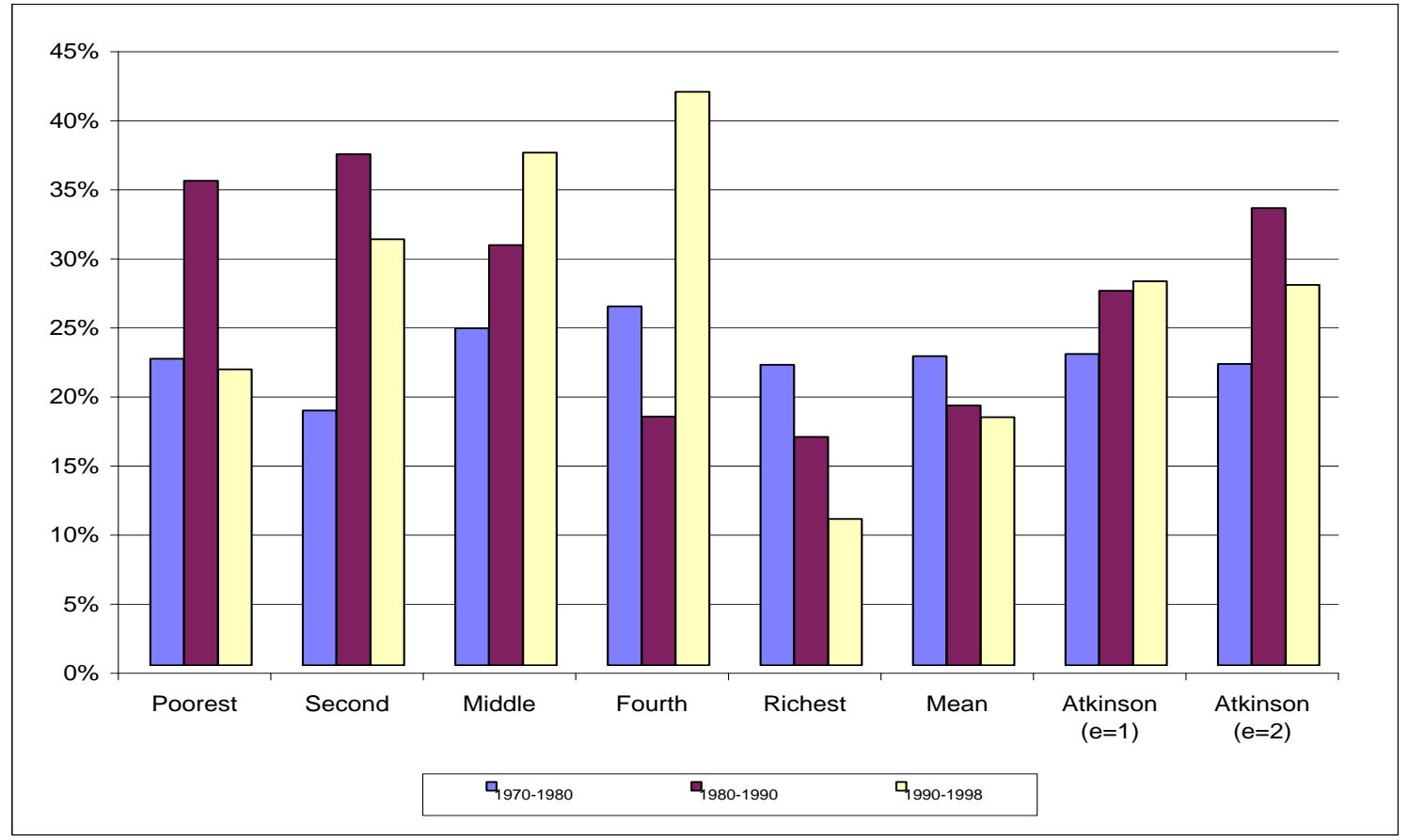

Figure 14: Growth in world well-being (including socialist countries), 1988-1998

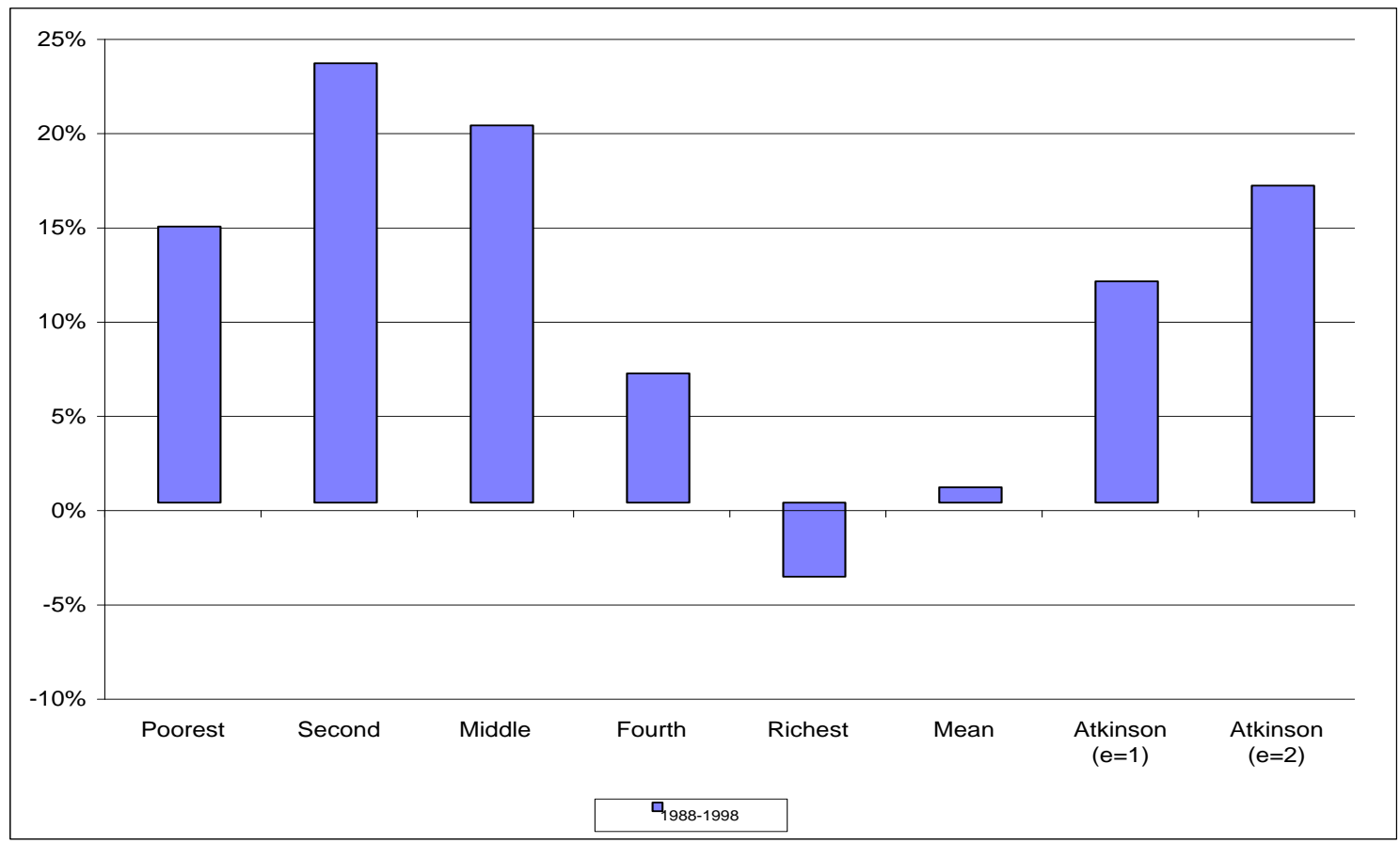




\section{CESifo Working Paper Series}

(for full list see www.cesifo.de)

772 Seppo Honkapohja and Kaushik Mitra, Learning Stability in Economies with Heterogenous Agents, September 2002

773 David Laidler, Inflation Targets Versus International Monetary Integration - A Canadian Perspective, September 2002

774 Morten I. Lau, Panu Poutvaara, and Andreas Wagener, The Dynamic Cost of the Draft, September 2002

775 Steven Brakman, Harry Garretsen, and Charles van Marrewijk, Locational Competition and Agglomeration: The Role of Government Spending, September 2002

776 Anke S. Kessler and Christoph Lülfesmann, The Theory of Human Capital Revisited: On the Interaction of General and Specific Investments, September 2002

777 Kjell Erik Lommerud, Frode Meland and Lars Sørgard, Unionized Oligopoly, Trade Liberalization and Location Choice, September 2002

778 Antonio Merlo and François Ortalo-Magné, Bargaining over Residential Real Estate: Evidence from England, September 2002

$779 \mathrm{Yu}-\mathrm{Fu}$ Chen and Michael Funke, Exchange Rate Uncertainty and Labour Market Adjustment under Fixed and Flexible Exchange Rates, September 2002

780 Michael S. Michael, International Migration, Income Taxes and Transfers: A Welfare Analysis, September 2002

781 Clemens Fuest and Alfons Weichenrieder, Tax Competition and Profit Shifting: On the Relationship between Personal and Corporate Tax Rates, October 2002

782 Jan Bouckaert and Hans Degryse, Softening Competition by Enhancing Entry: An Example from the Banking Industry, October 2002

783 Johann K. Brunner and Susanne Pech, Adverse Selection in the Annuity Market with Sequential and Simultaneous Insurance Demand, October 2002

784 Gregory D. Hess and Eduard Pelz, The Economic Welfare Cost of Conflict: An Empirical Assessment, October 2002

785 Jan Erik Askildsen, Uwe Jirjahn, and Stephen C. Smith, Works Councils and Environmental Investment: Theory and Evidence from German Panel Data, October 2002

786 Geir H. Bjønnes, Dagfinn Rime, and Haakon O. Aa. Solheim, Volume and Volatility in the FX-Market: Does it matter who you are?, October 2002 
787 John Evans and John Fingleton, Entry Regulation and the Influence of an Incumbent Special Interest Group, October 2002

788 Wolfgang Ochel, International Comparisons and Transfer of Labour Market Institutions, October 2002

789 B. Gabriela Mundaca, Moral Hazard Effects of Bailing out under Asymmetric Information, October 2002

790 Gene M. Grossman and Edwin L.-C. Lai, International Protection of Intellectual Property, October 2002

791 John Hassler, José V. Rodriguez Mora, Kjetil Storesletten, and Fabrizio Zilibotti, A Positive Theory of Geographic Mobility and Social Insurance, October 2002

792 Paul De Grauwe and Marianna Grimaldi, The Exchange Rate in a Model with Heterogeneous Agents and Transactions Costs, October 2002

793 Guido Friebel and Mariassunta Giannetti, Fighting for Talent: Risk-shifting, Corporate Volatility, and Organizational Change, October 2002

794 Jan Erik Askildsen, Badi H. Baltagi, and Tor Helge Holmås, Will Increased Wages Reduce Shortage of Nurses? A Panel Data Analysis of Nurses' Labour Supply, October 2002

795 Marko Köthenbürger and Panu Poutvaara, Social Security Reform and Intergenerational Trade: Is there Scope for a Pareto-Improvement?, October 2002

796 Paul De Grauwe and Laura Rinaldi, A Model of the Card Payment System and the Interchange Fee, October 2002

797 Volker Böhm and Tomoo Kikuchi, Dynamics of Endogenous Business Cycles and Exchange Rate Volatility, October 2002

798 Mariam Camarero, Javier Ordóñez, and Cecilio Tamarit, The Euro-Dollar Exchange Rate: Is it Fundamental?, October 2002

799 Misa Tanaka, How Do Bank Capital and Capital Adequacy Regulation Affect the Monetary Transmission Mechanism?, October 2002

800 Jörg Baten and Andrea Wagner, Autarchy, Market Disintegration, and Health: The Mortality and Nutritional Crisis in Nazi Germany, 1933-1937, October 2002

801 Saku Aura, Uncommitted Couples: Some Efficiency and Policy Implications of Marital Bargaining, October 2002

802 Wolfram F. Richter, Delaying Integration of Immigrant Labor for the Purpose of Taxation, October 2002

803 Gil S. Epstein and Shmuel Nitzan, The Politics of Randomness, October 2002 
804 John Hassler and José V. Rodriguez Mora, Should UI Benefits Really Fall over Time?, October 2002

805 Friedrich Breyer and Stefan Felder, The Dead-anyway Effect Revis(it)ed, October 2002

806 Assar Lindbeck and Solveig Wikström, E-exchange and the Boundary between Households and Organizations, November 2002

807 Dieter Bös, Contests Among Bureaucrats, November 2002

808 Steven Brakman, Harry Garretsen, and Marc Schramm, The Strategic Bombing of German Cities during World War II and its Impact on City Growth, November 2002

809 Florian Englmaier and Achim Wambach, Contracts and Inequity Aversion, November 2002

810 Sarbajit Sengupta, Delegating Recruitment under Asymmetric Information, December 2002

811 Rajshri Jayaraman, On the Partial Public Provision of a Private Good, December 2002

812 Stéphanie Stolz, Banking Supervision in Integrated Financial Markets: Implications for the EU, December 2002

813 Christian Keuschnigg, Taxation of a Venture Capitalist with a Portfolio of Firms, December 2002

814 Inés Macho-Stadler and David Pérez-Castrillo, Settlement in Tax Evasion Prosecution, December 2002

815 Rainer Niemann and Dirk Simons, Costs, Benefits, and Tax-induced Distortions of Stock Option Plans, December 2002

816 Jan-Egbert Sturm and Barry Williams, Deregulation, Entry of Foreign Banks and Bank Efficiency in Australia, December 2002

817 V. Anton Muscatelli, Patrizio Tirelli, and Carmine Trecroci, Monetary and Fiscal Policy Interactions over the Cycle: Some Empirical Evidence, December 2002

818 Claude Hillinger, A General Theory of Price and Quantity Aggregation and Welfare Measurement, December 2002

819 Erkki Koskela and Ronnie Schöb, Optimal Capital Taxation in Economies with Unionised and Competitive Labour Markets, December 2002

820 Sheilagh Ogilvie, Guilds, Efficiency, and Social Capital: Evidence from German ProtoIndustry, December 2002

821 Hans Gersbach and Verena Liessem, Financing Democracy, December 2002 
822 Costas Hadjiyiannis, Panos Hatzipanayotou, and Michael S. Michael, Optimal Tax Policies with Private-Public Clean-Up, Cross-Border Pollution and Capital Mobility, December 2002

823 François Ortalo-Magné and Sven Rady, Homeownership: Low Household Mobility, Volatile Housing Prices, High Income Dispersion, December 2002

824 Syed M. Ahsan and Panagiotis Tsigaris, Measuring the Social Discount Rate under Uncertainty: A Methodology and Application, December 2002

825 Kai A. Konrad, Altruism and Envy in Contests: An Evolutionarily Stable Symbiosis, December 2002

826 Robert S. Chirinko and Huntley Schaller, A Revealed Preference Approach to Understanding Corporate Governance Problems: Evidence from Canada, December 2002

827 Geir B. Asheim, Green National Accounting for Welfare and Sustainability: A Taxonomy of Assumptions and Results, December 2002

828 Andrea Gebauer, Chang Woon Nam, and Rüdiger Parsche, Lessons of the 1999 Abolition of Intra-EU Duty Free Sales for Eastern European EU Candidates, December 2002

829 Giacomo Corneo, Work and Television, December 2002

830 Vivek H. Dehejia and Yiagadeesen Samy, Trade and Labour Standards - Theory, New Empirical Evidence, and Policy Implications, December 2002

831 Geir B. Asheim and Wolfgang Buchholz, A General Approach to Welfare Measurement through National Income Accounting, December 2002

832 Aaron Tornell and Frank Westermann, The Credit Channel in Middle Income Countries, January 2003

833 Gebhard Flaig, Time Series Properties of the German Monthly Production Index, January 2003

834 Campbell Leith and Jim Malley, Estimated Open Economy New Keynesian Phillips Curves for the G7, January 2003

835 Burkhard Heer and Bernd Süssmuth, Inflation and Wealth Distribution, January 2003

836 Erkki Koskela and Leopold von Thadden, Optimal Factor Taxation under Wage Bargaining - A Dynamic Perspective, January 2003

837 Carola Grün and Stephan Klasen, Growth, Income Distribution, and Well-Being: Comparisons across Space and Time, January 2003 